\title{
ESR signal intensity of quartz in the fine-silt fraction of riverbed sediments from the Yangtze River: a provenance tracer for suspended particulate matter
}

\author{
Keita Saito ${ }^{1 *}$ (D, Ryuji Tada ${ }^{1}$, Hongbo Zheng ${ }^{2}$, Tomohisa Irino ${ }^{3}$, Chao Luo ${ }^{4}$, Mengying He ${ }^{4}$, Ke Wang $^{1}$ \\ and Yoshiaki Suzuki ${ }^{1}$
}

\begin{abstract}
The Asian summer monsoon exerts a strong influence on the hydrologic cycle in East Asia. Moreover, the distribution of heavy precipitation in the Yangtze River basin, which covers a large area of South China, is sensitive to changes in monsoon intensity. Thus, the paleo-distribution of heavy precipitation in the Yangtze basin is key in reconstructing the paleo-monsoon intensity. In this study, we established proxies for distinguishing sediments from the northwestern and southeastern parts of the Yangtze River basin, with the goal of using them to reconstruct the paleo-distribution of heavy precipitation in the basin based on changes in the provenance of detrital sediments, as determined using sediment records at the river mouth. The proxies included the electron spin resonance (ESR) signal intensity and the crystallinity index (Cl) of quartz in modern riverbed sediments along the mainstream and tributaries of the Yangtze River. The data revealed that the fine-silt fraction of the sediments (which represents suspended particulate matter, SPM) from each major tributary can be distinguished on the basis of ESR signal intensity and $\mathrm{Cl}$ values. The values for each tributary reflect the age and type of bedrock in the tributary basin and show distinct regional variations according to the distribution of geological blocks within the Yangtze basin. In addition, the analyzed ESR signal intensity and $\mathrm{Cl}$ values of the fine-silt fraction of riverbed sediments below mainstream-tributary junctions agree well with values calculated according to a simple mixing model of SPM discharged from the tributaries and the mainstream.
\end{abstract}

Keywords: Yangtze River, Riverbed sediment, Suspended particulate matter, Provenance, Electron spin resonance, Crystallinity index

\section{Introduction}

The Yangtze River is the longest river in Asia (length $>6300 \mathrm{~km}$ ), draining an area of $1.81 \times 10^{6} \mathrm{~km}^{2}$ (Hu et al. 2009) and with an annual water discharge of $910 \mathrm{~km}^{3} /$ year, which is the fifth largest in the world (Yang et al. 2002). More than 400 million people live in the Yangtze River drainage basin, and many large cities are situated along its mainstream (Zong and Chen 2000). According to historical records, more than 200 large floods have occurred on the Yangtze River over the last 2000 years, severely affecting the economies and lives of people in

\footnotetext{
* Correspondence: keitas@eps.s.u-tokyo.ac.jp

'Department of Earth and Planetary Science, University of Tokyo, 7-3-1

Hongo, Bunkyo, Tokyo 113-0033, Japan

Full list of author information is available at the end of the article
}

the region (Dai and Lu 2010). Because the drainage basin occupies a substantial portion of South China, which is under a temperate climate, more than $60 \%$ of the total precipitation within the drainage basin is discharged through the Yangtze River (Xu et al. 2010). Also, a positive correlation exists between annual and monthly precipitation in the basin and discharge of the Yangtze River (Xu et al. 2010). Water discharge of the Yangtze River during summer accounts for $71 \%$ of the annual discharge (Chen et al. 2001). During summer, precipitation in the middle to lower parts of the Yangtze drainage basin is affected by the East Asian summer monsoon (EASM), whereas precipitation in the uppermost part of the Yangtze River basin is sourced from the Indian summer monsoon (ISM), whose frontal position is connected 
to the EASM front (Wang and Lin 2002); thus, water discharge of the Yangtze River during summer reflects the amount of precipitation sourced from these monsoons. The EASM is characterized by a seasonal northwestward migration of its precipitation front, and the timing and extent of the migration are associated with migration of the westerly jet axis (Tada et al. 2016). Zhang et al. (2008) reported that inter-annual changes in the intensity of the EASM, which are defined by the strength of the northward wind around China, are associated with spatial changes in the location of the high-precipitation area, with its northwestward penetration being greatest during times of strong EASM convection. Thus, the reconstruction of past spatiotemporal changes in areas of heavy precipitation and flood within the Yangtze drainage basin is critical for understanding the long-term behavior of the EASM and ISM.

Suspended particulate matter (SPM) constitutes more than $95 \%$ of the sediments discharged from the Yangtze River (Chen et al. 2001). Because discharge of the Yangtze River reflects precipitation amounts in the drainage basin (Xu et al. 2010), and because a strong positive relationship exists between discharge and sediment load (Chen et al. 2001), we hypothesize that changes in the SPM provenance reflect changes in the distribution of high-precipitation areas. Based on this reasoning, changes in the provenance of sedimentary materials recorded at the Yangtze rivermouth could enable us to reconstruct the spatiotemporal variability of heavy-precipitation areas within the Yangtze drainage basin. Application of this technique to sediment archives collected from an area immediately outside the rivermouth is the ultimate goal of this study.

To identify the provenance of SPM, we analyzed the electron spin resonance (ESR) signal intensity and the crystallinity index (CI) of detrital quartz in three size fractions of riverbed sediments: 4-16, 16-63, and $>63 \mu \mathrm{m}$. The ESR signal intensity and CI values have been used to distinguish sources of sediments, such as eolian dusts from various deserts in western China (e.g., Nagashima et al. 2007; Sun et al. 2007). We focused on the quartz fraction because it is the most common mineral in detrital materials and is resistant to physical and chemical weathering. Moreover, its specific gravity is close to the average of detrital materials, meaning that size-sorting effects are minimal. The objectives of this study were to (i) characterize quartz in the sediments discharged from each tributary of the Yangtze River based on ESR signal intensity and CI values and (ii) test whether the relative contribution of detrital materials derived from different tributaries is accurately reflected in ESR signal intensity and CI values of quartz in sediments deposited along the mainstream and discharged from the rivermouth.

\section{Geographical setting}

The headwaters of the Yangtze River are on the Tibetan Plateau at an altitude of $>6000 \mathrm{~m}$. From the plateau, the river flows through the Sichuan Basin, the Three Gorges, and across the Jianghan Plain before draining into the East China Sea. In this study, we subdivided the mainstream of the Yangtze River into four parts using a modified version of the definition provided by Chen et al. (2001): uppermost, upper, middle, and lower (Fig. 1). The uppermost part is defined as the mainstream between the headwaters on the Tibetan Plateau and Yibin, the latter being located at the river's entrance to the Sichuan Basin. The uppermost part is a major contributor of SPM to the Yangtze River and is characterized by steep slopes of the riverbed and deep and steep valleys (Yang et al. 2006). The length of the uppermost part is $\sim 3100 \mathrm{~km}$ (Liu et al. 2011; Wu et al. 2009) and its drainage area is $4.6 \times 10^{5} \mathrm{~km}^{2}$ (Hu et al. 2009), constituting 25\% of the entire Yangtze drainage basin. The difference in altitude from the headwaters to the outlet of the uppermost part is $>4000 \mathrm{~m}$ (USGS 2004), and the average riverbed slope is $>1 \%$. The depth of the river valley reaches $2000 \mathrm{~m}$. A major tributary, the Yalongjiang flows into the mainstream from the north in the lower section of the uppermost part (Fig. 1). The "Big Bend" in Yunnan Province is situated where the mainstream turns from a southeastward to northeastward flow direction (Fig. 1).

The upper part, or the Chuanjiang, is defined as the mainstream between Yibin and Yichang, the latter being located just below the outlet of the Three Gorges. In the upper part, the mainstream runs through the southern part of the Sichuan Basin, then flows into the Three Gorges (Fig. 1). The length of the upper part is $\sim 800 \mathrm{~km}$ and its drainage area is $5.2 \times 10^{5} \mathrm{~km}^{2}$ (Hu et al. 2009), constituting $29 \%$ of the entire Yangtze River drainage basin. In the Sichuan Basin, the riverbed slope is 0.1$0.2 \%$ and the valley depth is $200-300 \mathrm{~m}$; both the riverbed slopes and the depths of valleys are smaller in the upper part than in the uppermost part. In the Three Gorges, the maximum riverbed slope and valley depth increase to $0.4 \%$ and $1000 \mathrm{~m}$, respectively (Chen et al. 2001; USGS 2004). The channel width in the upper part is $0.5-1.5 \mathrm{~km}$ and water depth is $5-20 \mathrm{~m}$ (Chen et al. 2001). In the Sichuan Basin portion of the upper part, two major tributaries, the Minjiang and Jialingjiang, flow into the mainstream from the north and one major tributary, the Wujiang, flows into the mainstream from the south. Construction of the Three Gorges Dam (TGD) was completed in 2003 on the mainstream at the outlet of the Three Gorges, upstream of Yichang.

The middle part, or the middle Yangtze, is defined as the mainstream between Yichang and Hukou, the latter being located just downstream of the Poyang Lake outlet. The length of the middle part is $950 \mathrm{~km}$ and its 


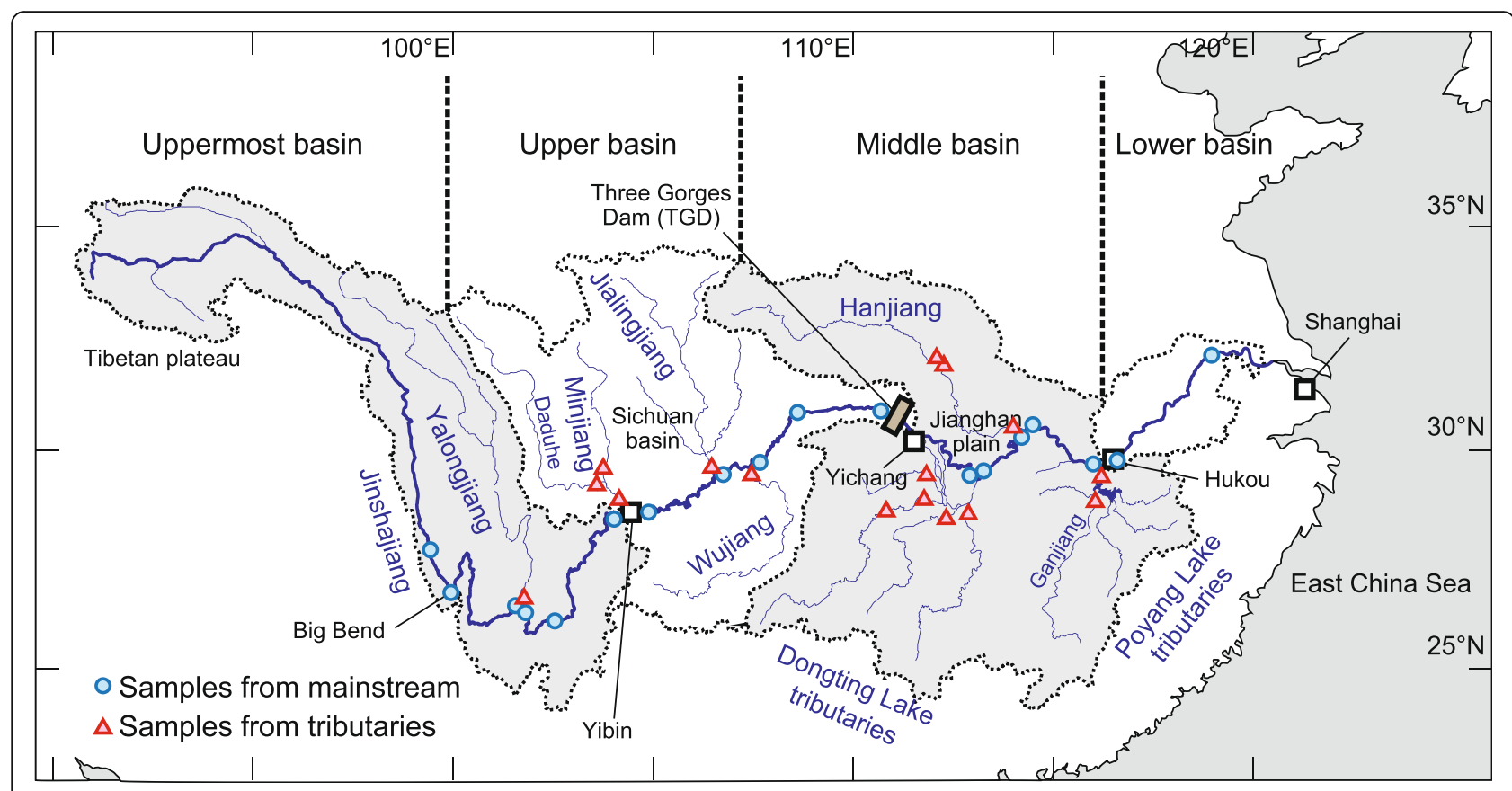

Fig. 1 Map of the Yangtze River drainage basin showing the locations of sampling sites in this study, and delineation of the uppermost, upper, middle, and lower parts of the mainstream and their drainage basins

drainage area is $6.8 \times 10^{5} \mathrm{~km}^{2}$, constituting $38 \%$ of the entire Yangtze River drainage basin (Chen et al. 2001). As it flows across the Jianghan Plain, the mainstream is characterized by a $10 \mathrm{~km}$ scale meandering channel, and the plain includes many lakes that originated as cutoff channels. The riverbed slope of the mainstream deceases dramatically in the middle part, to $0.02-0.03 \%$, and the channel widens to $1-2 \mathrm{~km}$, with a depth of 6-15 m (Chen et al. 2001). Three major tributaries flow into the mainstream in the middle part, the Hanjiang from the north and tributaries through the Dongting Lake and Poyang Lake drainages from the south (Fig. 1). The Dongting Lake drainage, with an area of $2.7 \times 10^{5} \mathrm{~km}^{2}$ (Hayashi et al. 2008), gathers waters from four major tributaries. In addition, three natural channels flow from the mainstream into Dongting Lake, known as the "Three Channels" or "Three Outlets" (Dai et al. 2005; Yin et al. 2007). Thus, some water and SPM in the upper part of the mainstream flow into Dongting Lake through these three channels (Dai et al. 2005). The area of the Poyang Lake drainage basin is $1.6 \times 10^{5} \mathrm{~km}^{2}$, and its largest tributary is the Ganjiang (Hu et al. 2007).

The lower part, or the lower Yangtze, is defined as the mainstream between Hukou and the rivermouth. Its length is $930 \mathrm{~km}$ and its drainage area is $1.2 \times 10^{5} \mathrm{~km}^{2}$ (Chen et al. 2001), constituting 7\% of the entire Yangtze River drainage basin. The mainstream in this part flows across flat plains and past low hills and is characterized by numerous braided channels (Chen et al. 2001). The riverbed slope in the lower part decreases to $0.01 \%$, and the channel width widens to an average of $2-4 \mathrm{~km}$, reaching a width of $15 \mathrm{~km}$ in the estuary region; the channel depth increases to 10-20 m (Chen et al. 2001). Although many lakes are situated near the mainstream, no large tributary exists in the lower part.

\section{Geologic setting}

A geological map of the Yangtze drainage basin is presented in Fig. 2. In the headwater region of the uppermost basin, the mainstream flows through the northern Qamdo Block, which is composed mainly of Triassic-Jurassic shallow-marine carbonate, basaltic, and fluvial sedimentary rocks (Yin and Harrison 2000; Xia et al. 2011). The mainstream then flows into the Songpan-Garze terrane, which is composed of Triassic turbiditic sedimentary rocks that were deposited in the Paleo-Tethys Ocean and folded during the Late Triassic (Enkelmann et al. 2007; Roger et al. 2008). The major tributary in the uppermost drainage basin, the Yalongjiang, also flows mainly through the Songpan-Garze terrane. The southwestern part of the uppermost Yangtze drainage basin, where the Jinshajiang flows southward parallel to the Lancanjiang (Mekong River) and Nujiang (Salween River), includes Paleozoic carbonates, mafic volcanics, and Permian-Paleogene shales and sandstones (Reid et al. 2005a). In the lower part of the uppermost basin below Big Bend, Permian-Triassic mafic igneous rocks known as the Emeishan large igneous province are extensively distributed in association with Jurassic sandstones and mudstones (Ali et al. 2005; Liu et al. 2011). 


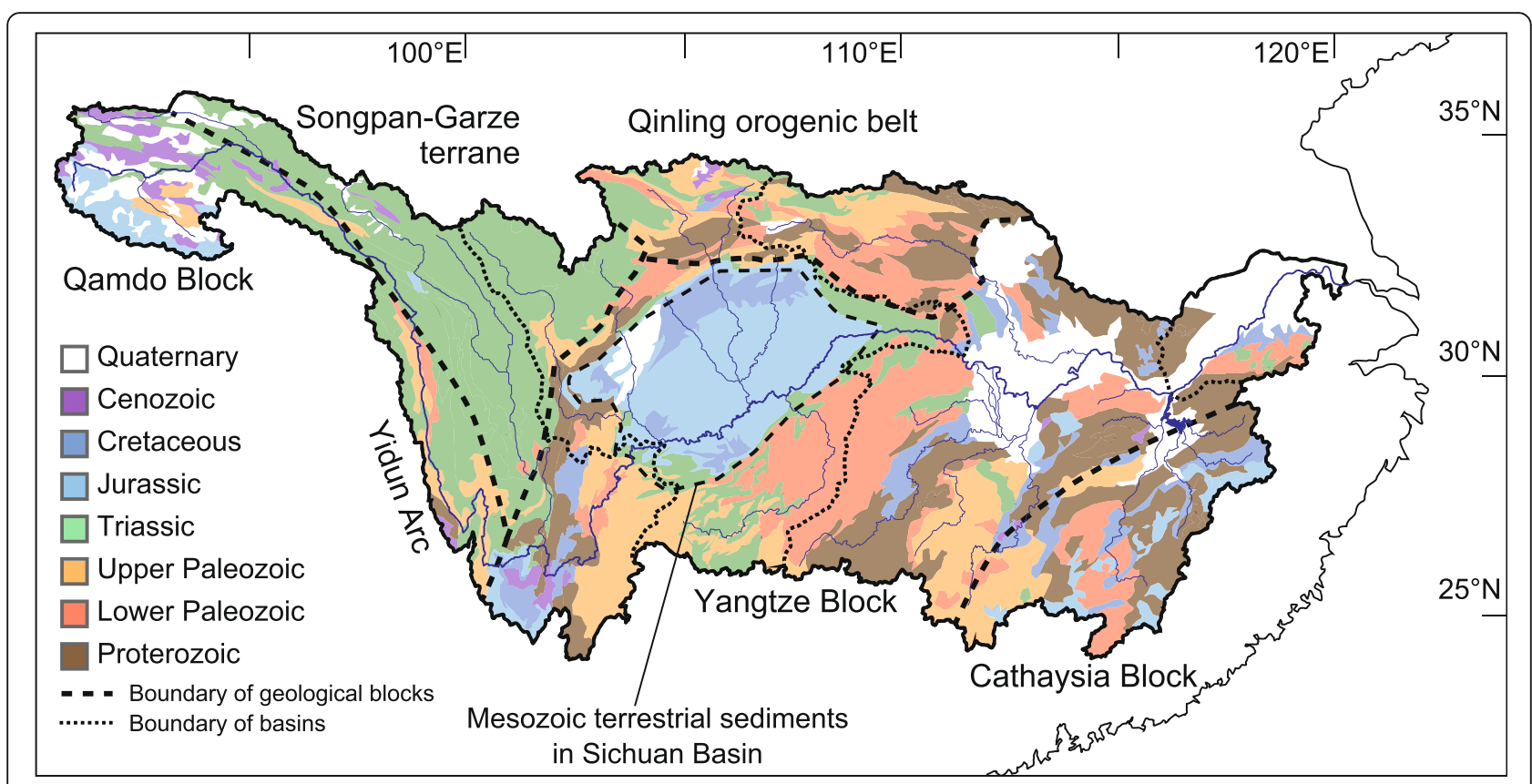

Fig. 2 Map showing ages of bedrock in the Yangtze drainage basin (after Teraoka and Okamura 2003, 2007)

The northwestern part of the upper Yangtze drainage basin, which is drained by the Daduhe (the largest tributary of the Minjiang; Fig. 1), is also underlain by the Songpan-Garze terrane, where it is composed mainly of Triassic turbiditic rocks that are partly intruded by Late Triassic or Early Jurassic granites (Reid et al. 2005a; Roger et al. 2008). The upper part of the Jialingjiang drainage basin belongs to the South Qinling orogenic belt, consisting of Meso-Neoproterozoic basement that was weakly metamorphosed during the Neoproterozoic, shallowmarine deposits of Neoproterozoic-Devonian age, and Triassic granitoids (Meng and Zhang 2000; Qin et al. 2010; Dong et al. 2011). The central to southeastern Sichuan Basin, which is drained by the middle to lower part of the Jialingjiang and the lower part of the Wujiang, is widely covered by thick terrestrial mudstone and sandstone deposited during the Jurassic-Cretaceous (Hao et al. 2008; Ma et al. 2008). The upper part of the Wujiang drainage basin is underlain by Permian-Triassic limestones and dolomitic limestones with minor basalts. Cambrian and Ordovician carbonates and Silurian sandstones are exposed mainly in the lower part of the Wujiang drainage basin (Han and Liu 2004; Wang et al. 2010).

In the middle Yangtze drainage basin, Quaternary sediments transported by the Yangtze are widely deposited along the mainstream, particularly across the Jianghan Plain between the mainstream and the Hanjiang. The upper part of the Hanjiang drainage basin belongs to the Qinling orogenic belt and is composed of Neoproterozoic basement and Neoproterozoic-Devonian sediments (Qin et al. 2010). Quaternary loess deposits also occur in some parts of the upper Hanjiang drainage basin (Zhang et al. 2012). The Jianghan Plain forms the middle to lower part of the Hanjiang drainage basin. Most of the Dongting Lake drainage basin belongs to the eastern part of the Yangtze Block. The Proterozoic basement of the Yangtze Block has been subjected to low-grade metamorphism. Cambrian and Ordovician carbonate rocks, Devonian sandstone and shale, and Cretaceous redcolored sandstone are the main rocks exposed in this region (Chen and Jahn 1998; Wang et al. 2010, 2013). The drainage basin of Poyang Lake and the easternmost part of the Dongting Lake drainage basin belong to the Cathaysia Block, which is composed of Neoproterozoic conglomerate and sandstone, lower Paleozoic siliciclastics, Jurassic granites, and Cretaceous red-colored sandstone (Wang et al. 2007a, 2013).

In the lower Yangtze drainage basin, Quaternary sediments derived from the upper and middle Yangtze were deposited along the mainstream. The southern part of the lower Yangtze drainage basin belongs to the Cathaysia Block (Wang et al. 2007a, 2013).

In summary, the bedrock of the uppermost and upper Yangtze drainage basins is relatively young and is composed mainly of Mesozoic strata, while the northernmost and southern parts of the upper Yangtze drainage basin are composed mainly of Paleozoic strata, and the middle and lower Yangtze drainage basins are composed mainly of Paleozoic-Proterozoic strata (Fig. 2). Thus, the strata in the Yangtze drainage basin tend to increase in age downstream. Regarding rock types, sedimentary and low-grade metasedimentary rocks are exposed mainly in 
the uppermost and upper parts of the basin, whereas crystalline plutonic rocks are more common in the middle and lower parts of the basin.

\section{Hydrologic setting}

In the Yangtze basin, hydrological observations of water discharge and sediment load began in the 1870 s and 1950s, respectively (Chen et al. 2001). Measurements of water flow speed and cross-sectional area are conducted daily by ships at major gauging stations along the mainstream and major tributaries (Wang et al. 2007b; Hassan et al. 2010). At each station, the sediment load is calculated as the product of suspended sediment concentration and water discharge (Yang et al. 2006). Figures 3 and 4 show the annual sediment budget for the entire drainage basin averaged over the periods 1950-2002 (before operation of the TGD) and 2003-2012 (after the start of operation of the TGD) (Dai et al. 2005; Yang et al. 2006, 2014; Hu et al. 2009).

Dongting Lake, which drains into the middle part of the mainstream, has played an important role in the sediment budget of the Yangtze (Dai et al. 2005). In particular, below the Three Gorges, turbid water from the upper part flows not only into the mainstream of the Yangtze but also into channels flowing into Dongting Lake, known as the Three Outlets (Dai et al. 2005; Yin et al. 2007). Therefore, Dongting Lake receives sediments from the mainstream above the Three Gorges through the Three Outlets, in addition to sediment originating from its own tributaries. Thus, the sediments discharged from Dongting Lake to the mainstream are a mixture of sediments from the upper part of the mainstream and from tributaries flowing into Dongting Lake itself. According to observational data, the volume of sediments accumulating in Dongting Lake is proportional to the inflow volume from the Three Outlets: it is estimated that $87 \%$ of sediments flowing into the Three Outlets were deposited in the Dongting Lake area during 1950-2002 (Dai et al. 2005).

Since the 1950s, when observations of sediment load began, sediment discharge in the mainstream at Datong has shown a decreasing trend, owing to reservoir construction and the National Soil Conservation Project, particularly in the Jialingjiang drainage basin (Yang et al. 2006; $\mathrm{Hu}$ et al. 2011). Moreover, the start of operations of the TGD in 2003 significantly changed the sediment budget in the mainstream below the TGD (Figs. 3 and 4). Before the start of TGD operations, the total sediment input into the Three Gorges area was $489 \mathrm{Mt} /$ year, which nearly balanced the sediment load of $492 \mathrm{Mt} /$ year at Yichang (Yang et al. 2007). However, since operation of the TGD, $80.3 \%$ (188 Mt/year) of the sediments flowing into the Three Gorges area (234 Mt/year) have been trapped by the TGD (Yang et al. 2014). The sediment budget in the middle and lower parts of the Yangtze also changed after 2003 on account of the TGD, because of decreased sediment loads from the upper to the middle and lower parts (Chang et al. 2010). Specifically, the middle and lower parts have experienced erosion of $63 \mathrm{Mt} /$ year since the start of TGD operations in 2003, whereas prior to 2003, these regions experienced a net sediment accumulation of $36.1 \mathrm{Mt} /$ year (Dai et al. 2005; Yang et al. 2014). In the 2010s, more than 10 hydropower reservoirs were proposed in the uppermost part of the basin. Five dams had been constructed on the mainstream by 2012, including the Xiangjiaba and Xiluodu Dams between the Yibin and Yalongjiang tributaries, and the Longkaikou, Jinangqiao, and Ahai Dams between the Yalongjiang and Big Bend (Hennig et al. 2013). Operation of the Jinangqiao Dam began prior to 2010, while construction of the other dams started in the early 2010s. These dams are expected to influence the sediment budget in the uppermost Yangtze in the near future.

\section{Methods/Experimental Samples}

Riverbed sediments were sampled mainly from the riverside of the mainstream and major tributaries of the Yangtze in July and September 2011 and in February and October 2012. Sediments from the mainstream were

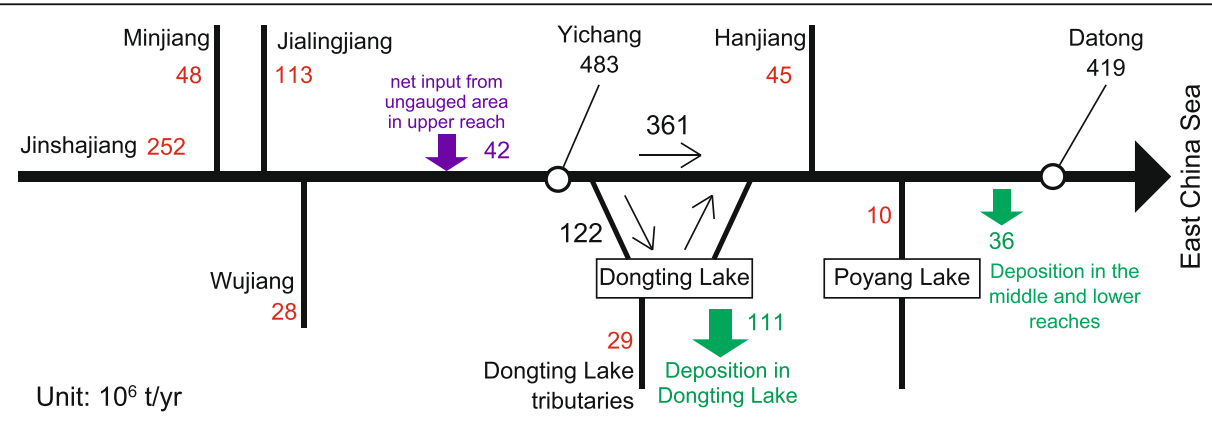

Fig. 3 Average annual sediment budget in the Yangtze drainage basin during 1950-2002, before construction of the Three Gorges Dam (TGD) (based on Dai et al. 2005; Yang et al. 2006; Hu et al. 2009). Green arrows show deposition in the mainstream and lakes. Purple arrow shows sediment inputs from ungauged areas 


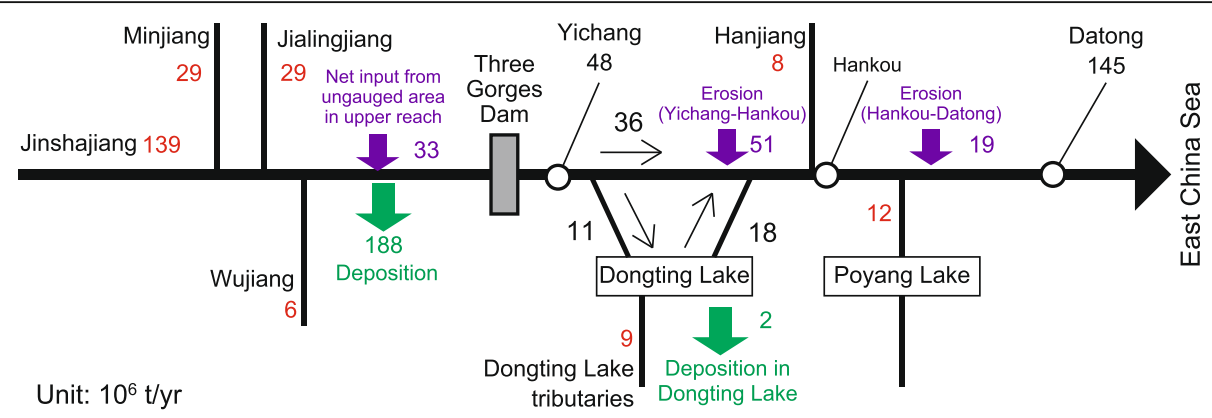

Fig. 4 Average annual sediment budget in the Yangtze drainage basin during 2003-2012, after construction of the Three Gorges Dam (TGD) (based on Yang et al. 2014). Green arrows show deposition in the mainstream and lakes. Purple arrows show sediment inputs from ungauged areas

sampled at locations a few hundred meters to a few kilometers above and below the junctions with major tributaries to evaluate the effects of sediment mixing between the mainstream and the tributaries. Sediments from the tributaries were sampled at locations several kilometers upstream of the junction with the mainstream so as to prevent contamination of sediments from the mainstream. Our data show that in the lower part, the SPM consists of fine silt particles with a mean diameter of $\sim 10 \mu \mathrm{m}$ throughout the year (Hassan et al. 2010; Mao et al. 2011). Furthermore, SPM accounts for $98 \%$ of the sediment discharge from the Yangtze rivermouth (Yang et al. 2002). For these reasons, we sampled silty sediments wherever possible and otherwise sampled sandy sediments.

We also analyzed three SPM samples (JSJ-GLS, JSJ110701, and YZ110703-03; Additional file 1) obtained at the same locations and on the same days as the riverbed samples were taken. Then, we examined if the composition of the fine-silt fraction of the riverbed samples could be used as a proxy of the SPM.

\section{Sample preparation}

Samples were pretreated prior to grain size separation based on methods presented by Rea and Janecek (1981) and Tada et al. (2000). Approximately $3 \mathrm{~g}$ of dry sample was placed into each of two plastic centrifuge tubes. In the first step, carbonates were removed by immersion in $50 \mathrm{ml}$ of $20 \%$ acetic acid at room temperature for $8 \mathrm{~h}$. After removing carbonates, the supernatants were drained. Approximately $50 \mathrm{ml}$ of deionized water was added, and the tubes were centrifuged twice at $3000 \mathrm{rpm}$ to remove any remaining acetic acid. In the second step, organic matter was removed by immersion in $~ 50 \mathrm{ml}$ of $10 \%$ hydrogen peroxide at $60{ }^{\circ} \mathrm{C}$ for more than $20 \mathrm{~h}$ until all bubbling ceased. After the supernatant was drained, $\sim 50 \mathrm{ml}$ of deionized water was added and the tubes were centrifuged twice at $3000 \mathrm{rpm}$. In the third step, Fe and Mn oxides were removed using a mixture of $0.3 \mathrm{~mol} / \mathrm{l}$ sodium citric acid and $0.1 \mathrm{~mol} / \mathrm{l}$ sodium hydrogen carbonate at a ratio of
8:1, followed by the addition of $3 \mathrm{~g}$ of sodium hydrosulfite. The tubes were heated at $80{ }^{\circ} \mathrm{C}$ for $8 \mathrm{~h}$. Then, the supernatant was removed, $50 \mathrm{ml}$ of deionized water was added, and the tubes were centrifuged twice.

These pretreated samples were kept wet until the grain-size separation procedure. Grain size separation was conducted by the settling method based on Stokes' law at 4 and $16 \mu \mathrm{m}$. Separation at $63 \mu \mathrm{m}$ for the $>16 \mu \mathrm{m}$ fraction was also conducted using a sieve. Although we did not sieve the upper limit of the $>63 \mu \mathrm{m}$ fraction, the grain size in the sand fraction was not larger than 2-3 $\mathrm{mm}$, based on macroscopic observation. The riverbed sediments were separated into four size fractions: $<4 \mu \mathrm{m}$ (clay), 4-16 $\mu \mathrm{m}$ (fine-silt), 16-63 $\mu \mathrm{m}$ (coarsesilt), and $>63 \mu \mathrm{m}$ (sand); the latter three fractions were analyzed. The SPM samples were separated into two size fractions: $<4$ and $>4 \mu \mathrm{m}$, and the latter was analyzed. The $<4 \mu \mathrm{m}$ (clay) fraction was not analyzed, either in the riverbed sediments or in the SPM. After completion of the separation procedures, each fraction was dried and weighed.

\section{ESR analysis}

The ESR signal intensity of quartz was used to constrain the provenance of quartz in the sediments. The ESR signal intensity of the $E_{1}{ }^{\prime}$ center of quartz reflects the number of unpaired electrons accompanied by an oxygen vacancy (Feigl et al. 1974; Toyoda and Naruse 2002). As these oxygen vacancies in quartz are formed mainly by natural radiation generated by radioactive elements in the host rock, the ESR signal intensity increases with the age of the host rock (Toyoda and Naruse 2002).

Prior to the ESR signal intensity measurement, electron holes were created in dried sediment grains by irradiating with $2.5 \mathrm{kGy}{ }^{60} \mathrm{Co} \gamma$-rays at room temperature, at the Takasaki Advanced Radiation Research Institute, National Institutes for Quantum and Radiological Science and Technology, Takasaki, Japan, according to the method of Toyoda and Hattori (2000). Then, $\sim 0.1 \mathrm{~g}$ of sample was heated at $300{ }^{\circ} \mathrm{C}$ for $15 \mathrm{~min}$ to convert the oxygen vacancy 
of quartz to the $\mathrm{E}_{1}{ }^{\prime}$ center. The ESR measurements were conducted using an ESR spectrometer (FA-100, JEOL) at the Department of Earth and Planetary Science, University of Tokyo, Tokyo, Japan. The measurement conditions were a microwave strength of $0.01 \mathrm{~mW}$, a measurement range of $5 \times 1 \mathrm{mT}$, a measurement time at room temperature of $2 \mathrm{~min}$, and a sample weight of $0.1 \pm$ $0.001 \mathrm{~g}$. The ESR signal intensity of the bulk sample was normalized by the weight percent of quartz in the sample to obtain the ESR signal intensity of the quartz (unit, $1.3 \times 10^{15} \mathrm{spins} / \mathrm{g}$ ) (Toyoda and Hattori 2000).

To evaluate the reproducibility of the ESR signal intensity data, we selected two $\gamma$-ray-irradiated samples (consisting of the fine-silt fractions of samples YZ1210-4 and YZ110703-04m2; Additional file 1), split each sample into three subsamples, packed each subsample into a discrete holder, and then measured the ESR signal intensity of quartz in each subsample. The standard error (95\%) for each sample was calculated based on three measurements on each of the three subsamples (nine measurements in total). The reproducibility of the ESR signal intensity results was represented by a standard error of 1.3 for sample YZ110703-04m2 and 3.0 for sample YZ1210-4. We adopted the average of these standard errors (2.2) as the reproducibility of the ESR signal intensity data obtained in this study.

\section{X-ray powder diffraction analysis}

The quartz content (QC) was determined using X-ray power diffraction (XRD) to calculate the ESR signal intensity of quartz. The CI was also determined by XRD, to correct for crystallinity effects on the quartz peak height. The CI is an index of the degree of crystallization of quartz, as it reflects conditions of crystallization, such as cooling speed and crystallization temperature (Murata and Norman 1976). The CI values were calculated as the degree of the quartz peak split at $67.74^{\circ} 2 \theta$, based on the definition of Murata and Norman (1976). The CI was also used to constrain the provenance of quartz. Prior to the XRD measurements, two size fractions (16-63 and $>63 \mu \mathrm{m}$ ) were ground to powder for $\sim 15$ min using an agate mortar; the fine-silt fraction $(4-16 \mu \mathrm{m})$ was not ground, as it was considered sufficiently small for XRD analysis. To measure the QC, $10.0 \mathrm{wt}$.\% of silicon powder was added to the samples as an internal standard. The XRD measurement (X'pert Plus, PANalytical) was conducted at the Department of Earth and Planetary Science, University of Tokyo. The XRD measurements were repeated three times with repacking, each time using $\mathrm{CuK} \alpha \mathrm{X}$-rays, at a voltage of $45 \mathrm{kV}$ and a current of $40 \mathrm{~mA}$; results for each sample were averaged. The divergence and anti-scatter slits were 1.52 and $3 \mathrm{~mm}$ in width, respectively. The measurement ranges were $20-30^{\circ}$ $2 \theta$ for QC and $66-71^{\circ} 2 \theta$ for CI. The QC was calculated as the ratio of the silicon and quartz peak heights at $27.9^{\circ}$ $2 \theta$ and $20.9^{\circ} 2 \theta$. The QC was also corrected for the effect of crystallinity based on the method of Isozaki (2009).

The reproducibility of the $\mathrm{CI}$ values was evaluated for two $\gamma$-ray-irradiated samples (the fine-silt fractions of samples YZ1210-4 and YZ110703-04m2; Additional file $1)$. We collected three subsamples from each of the two irradiated samples. Each subsample was split and packed into an XRD holder and measured by XRD. The CI value for each subsample was calculated as the average of three measurements. Therefore, we collected nine CI measurements for each irradiated sample, and the standard error for each irradiated sample was based on the three CI measurements of the subsamples. The standard error was 0.23 for sample YZ1210-4 and 0.34 for sample YZ110703-04m2. We adopted the average of these standard errors (0.29) as the reproducibility of the CI values.

\section{Results and Discussion \\ ESR signal intensity of quartz in riverbed sediments Fine-silt (4-16 $\mu \mathrm{m})$ fraction}

Figure 5a shows the geographical distribution of the ESR signal intensity of quartz in the fine-silt fraction in the Yangtze drainage basin. Samples collected from the mainstream show ESR signal intensities of 0.0-9.4, with an average of 3.9. The ESR signal intensities of samples collected from the mainstream increase from $0.0-2.3$ in the uppermost part to 3.1-5.7 in the lower part; however, values in the uppermost part above Big Bend are $\sim 8$. Samples collected from the Yalongjiang and Minjiang show ESR signal intensities of 0.0-5.5, with an average of 2.2 , which is similar to values from the upper part of the mainstream, while samples collected from the Jialingjiang and Wujiang show ESR signal intensities of 1.5-15.5, with an average of 10.3, which is higher than values from the upper part of the mainstream. Samples collected from the tributaries in the middle part show a wide range of ESR signal intensities, from 0.0 to 23.4 with an average of 9.2, which is higher than values from the middle part of the mainstream.

\section{Coarse-silt (16-63 $\mu \mathrm{m})$ fraction}

Figure $5 \mathrm{~b}$ shows the geographical distribution of ESR signal intensities of quartz in the coarse-silt fraction in the Yangtze drainage basin. Samples collected from the mainstream show ESR signal intensities of 0.0-5.8, with an average of 2.6. Samples collected from the Yalongiiang and Minjiang show ESR signal intensities of 0.0-2.4, with an average of 1.2, which is similar to values from the upper part of the mainstream, while samples collected from the Jialingjiang and Wujiang show ESR signal intensities of 3.4-9.5, with an average of 5.2, which is higher than values from the upper part of the mainstream. 


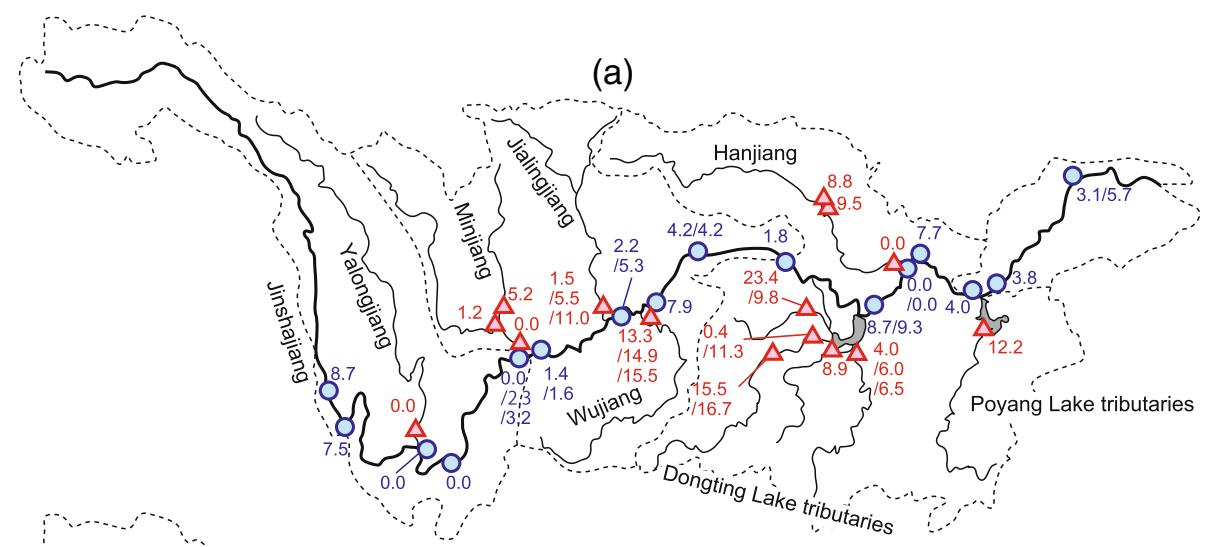

(b)

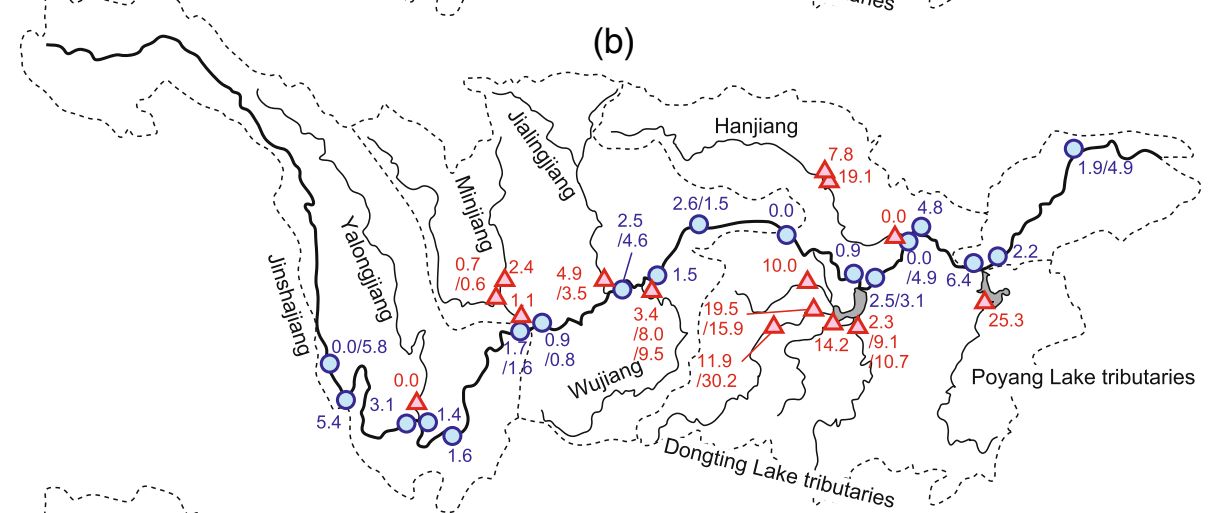

(c)

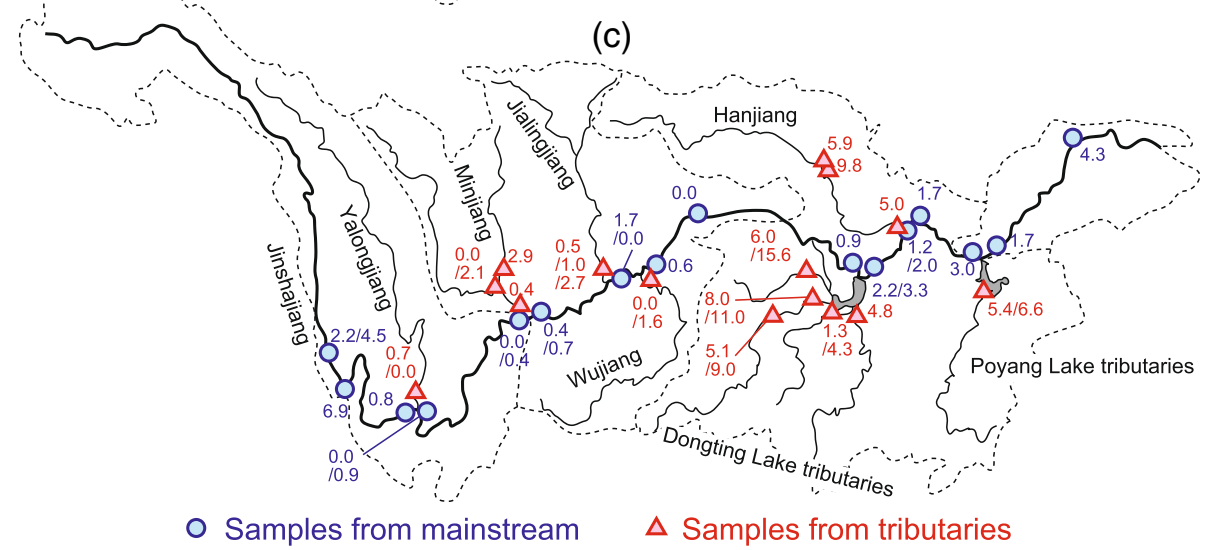

Fig. 5 Geographical distribution of electron spin resonance (ESR) signal intensity of quartz in riverbed samples. a Sand (>63 $\mu$ m) fraction. b Coarse-silt $(16-63 \mu \mathrm{m})$ fraction. c Fine-silt $(4-16 \mu \mathrm{m})$ fraction. The "/" separates the values of different samples collected from sites in close proximity to one another

Samples collected from tributaries in the middle part show a wide range of ESR signal intensities, from 0.0 to 30.2 , with an average of 11.2 , which is higher than values from the middle part of the mainstream.

\section{Sand ( $>63 \mu \mathrm{m})$ fraction}

Figure $5 \mathrm{c}$ shows the geographical distribution of ESR signal intensities of quartz in the sand fraction of riverbed samples from the Yangtze drainage basin. Samples collected from the mainstream show ESR signal intensities of 0.0-6.9, with an average of 1.6. The ESR signal intensities of samples collected from the mainstream increase from $0.0-0.9$ in the uppermost part to $1.8-4.8$ in the lower part, except in the uppermost part above Big Bend, where values are in the range of 2.26.9. Samples collected from tributaries in the uppermost and upper parts show lower ESR signal intensities (0.02.9 , with an average of 1.1) than those observed in the uppermost and upper parts of the mainstream. Samples collected from tributaries in the middle part show a wide 
range of ESR signal intensities, from 0.0 to 15.6, with an average of 5.4, which is higher than values from the middle and lower parts of the mainstream.

\section{$\mathrm{Cl}$ of quartz in riverbed sediments}

\section{Fine-silt (4-16 $\mu \mathrm{m})$ fraction}

Figure 6a shows the geographical distribution of CI values of quartz in the fine-silt fraction, which are in the range of 6.8-9.0, with an average of 8.5 and a standard deviation of 0.4 .
Samples collected from the mainstream show CI values of 6.8-9.0, with an average of 8.4, and display no obvious downstream trends. In the uppermost and upper parts, samples collected from the Yalongjiang and Daduhe show low CI values of 8.2-8.3, while samples collected from the Minjiang, Jialingjiang, and Wujiang show relatively high CI values of 8.6 to 8.9 , with an average of 8.7. Samples collected from the tributaries in the middle part show a wide range of CI values of 8.0-8.9, with an average of 8.5. Among the tributaries, some samples from the Minjiang, Wujiang, Dongting Lake

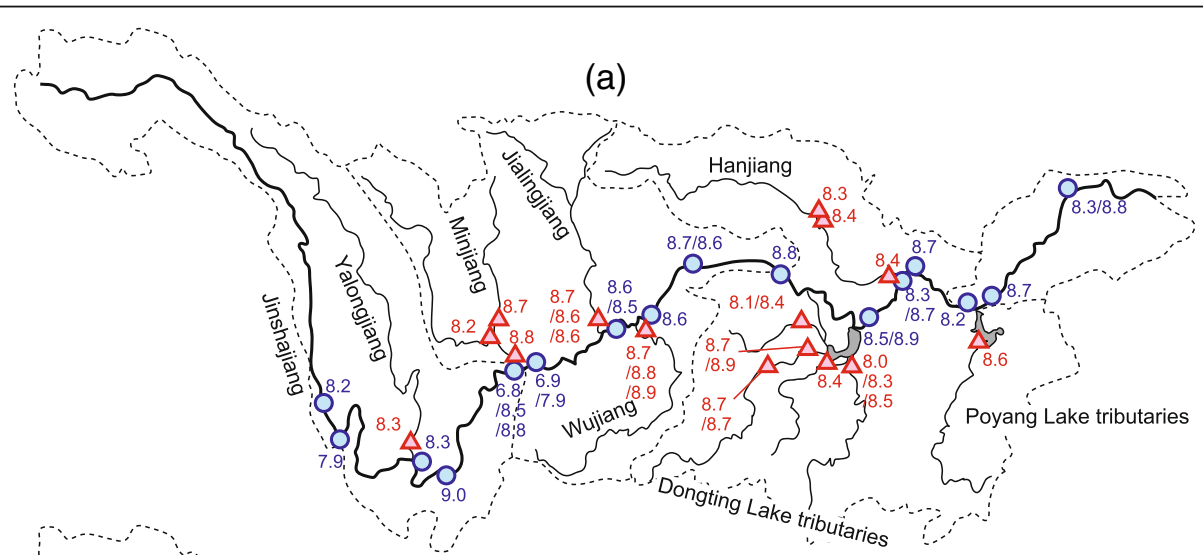

(b)

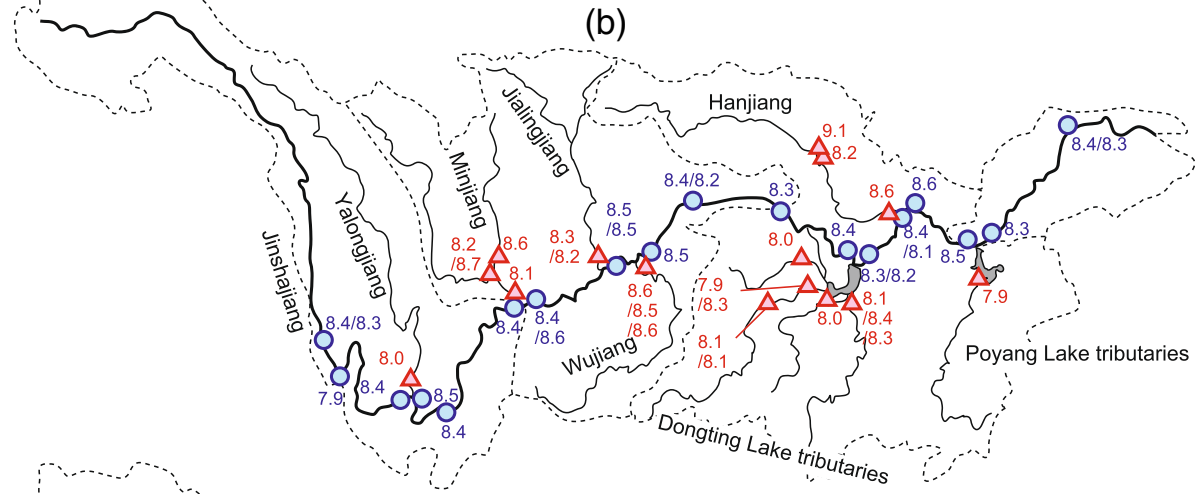

(c)

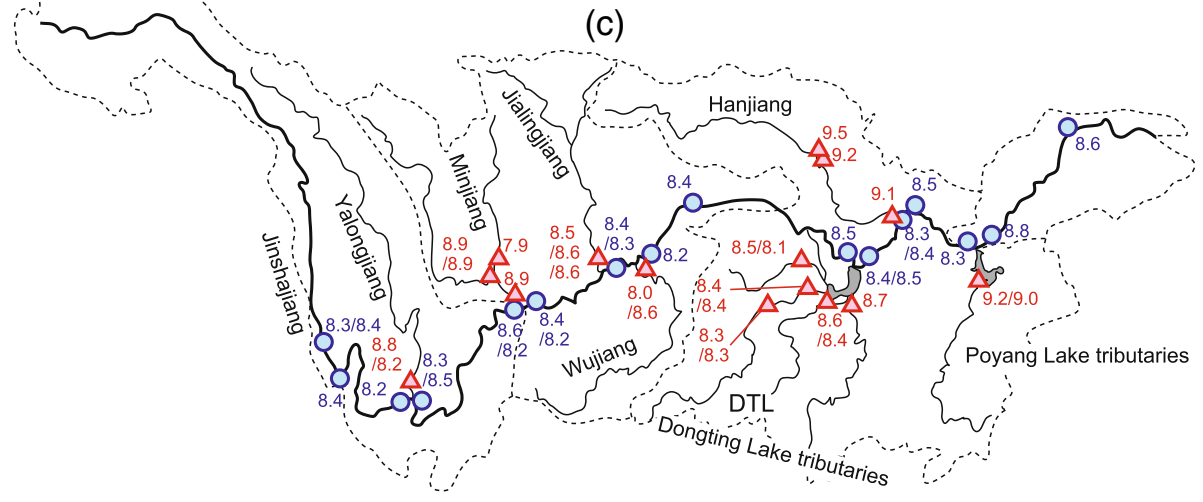

O Samples from mainstream

$\Delta$ Samples from tributaries

Fig. 6 Geographical distribution of crystallinity index (Cl) values of quartz in riverbed samples. a Sand (>63 $\mu$ m) fraction. b Coarse-silt (16-63 $\mu m$ ) fraction. c Fine-silt $(4-16 \mu \mathrm{m})$ fraction. The "/" separates values of different samples collected from sites in close proximity to one another 
tributaries, and Poyang Lake tributaries show relatively high CI values of $\sim 9$.

\section{Coarse-silt (16-63 $\mu \mathrm{m})$ fraction}

Figure $6 \mathrm{~b}$ shows the geographical distribution of CI values of quartz in the coarse-silt fraction in the Yangtze drainage basin. Samples collected from the mainstream show CI values of 7.9-8.6, with an average of 8.4 and show no clear downstream trends. Samples collected from the tributaries in the uppermost and upper parts show a wide range of $\mathrm{CI}$ values, from 7.9 to 8.7 , with an average of 8.4. Samples from tributaries in the middle part also show a wide range of CI values, from 7.9 to 9.1, with an average of 8.3. Among the tributaries, a sample from the Hanjiang is characterized by relatively high $\mathrm{CI}$ values of $\sim 9$, while samples from the Dongting Lake and Poyang Lake tributaries are characterized by low CI values of $\sim 8$.

\section{Sand $(>63 \mu \mathrm{m})$ fraction}

Figure $6 \mathrm{c}$ shows the geographical distribution of CI values of quartz in the sand fraction in the Yangtze drainage basin. Samples collected from the mainstream show CI values of $8.2-8.8$ with an average of 8.4 and a slightly increasing downstream trend from 8.3 to 8.7 , although with some scatter. Samples collected from the tributaries in the uppermost and upper parts show a wide range of $\mathrm{CI}$ values, from 7.8 to 8.9 , with an average of 8.5. Samples from tributaries in the middle part also show a wide range of CI values, from 8.1 to 9.5 , with an average of 8.7. Among the tributaries, some samples from the Minjiang, Dongting Lake, Hanjiang, and Poyang Lake tributaries are characterized by relatively high CI values of $\sim 9$.

\section{Comparisons of ESR signal intensities among the three size fractions}

Figure 7 shows differences between ESR signal intensities for the various size fractions in the same sample collected from the major tributaries. A comparison of the fine-silt and sand fractions reveals that ESR signal intensities for samples from the Jinshajiang, Minjiang, and Hanjiang are similar to one another, whereas intensities for samples from the Jialingjiang, Wujiang, Dongting Lake, and Poyang Lake tributaries are higher in the finesilt fraction than in the sand fraction (Fig. 7a). On the other hand, ESR signal intensities in the fine-silt and coarse-silt fractions in samples from the Jinshajiang and Minjiang are similar. Samples from the Jialingjiang and Wujiang show higher ESR signal intensities in the fine-silt fraction than in the coarse-silt fraction. Many of the samples from the Hanjiang, Dongting Lake, and Poyang Lake tributaries show similar values for the fine-silt and coarsesilt fractions. However, some samples from the Dongting
Lake drainage basin show higher ESR signal intensities in the fine-silt fraction, while some samples collected from the Hanjiang, Dongting Lake, and Poyang Lake drainage basins show higher ESR signal intensities in the coarse-silt fraction (Fig. 7b). The different ESR signal intensities among the three size fractions suggest origins from different source rocks. Thus, grain size should be considered when discussing the provenance of sediments.

Comparison of ESR signal intensities between the fine-silt fraction of riverbed samples and that of SPM samples

Although the modal diameter of SPM is within the range of the fine-silt $(4-16 \mu \mathrm{m})$ fraction, the coarse-silt $(16-63 \mu \mathrm{m})$ and very fine sand $(63-125 \mu \mathrm{m})$ fractions are also transported as suspension in addition to the clay $(<4 \mu \mathrm{m})$ and fine-silt $(4-16 \mu \mathrm{m})$ fractions (Mao et al. 2010; Gao et al. 2015). Therefore, we examined whether the fine-silt fraction of riverbed samples could be used as a proxy for SPM, by comparing their ESR signal intensities.

Three SPM samples were analyzed for comparison of their ESR signal intensities with those of riverbed sediments; the SPM and riverbed samples were collected at the same locality and on the same day. The ESR signal intensities of the SPM samples of 7.9, 5.6, and 3.4 (JSJ-GLS, JSJ110701, and YZ110703-03, respectively; Additional file 1) agree within errors with the intensities of the corresponding riverbed samples of 8.7, 2.3, and 3.9 (samples UYZ110911-01m, YZ110701-01c, and YZ110703-04m, respectively; Additional file 1). Thus, the ESR signal intensities of quartz in the fine-silt $(4-16 \mu \mathrm{m})$ riverbed sediments basically could be used as a proxy for the SPM samples.

Relationship between ESR signal intensity and $\mathrm{Cl}$ values of riverbed sediments, and the ages and types of bedrock in tributary basins

We summarize ESR signal intensity and CI values of sediments collected from each tributary (presented in Fig. 8) and examine their relationship with ages and types of bedrocks exposed in the respective drainage basins. As the basement rocks in each geological block are generally considered as the source of younger detrital sediments in the block, each sample is categorized with respect to the geological block(s) exposed in its drainage basin (Fig. 8). The geological blocks that make up the basement rocks in the Yangtze River drainage basin are classified into the Qamdo Block and Yidun Arc (QY), Songpan-Garze terrane (SG), Qinling orogenic belt (QL), Yangtze Block (YZ), and Cathaysia Block (CX). In addition, Quaternary sediments in the middle to lower parts are classified as a sixth type (Q). Mesozoic terrestrial sediments in the Sichuan Basin, which unconformably overlie basement rocks, are considered to be derived from 
(a)

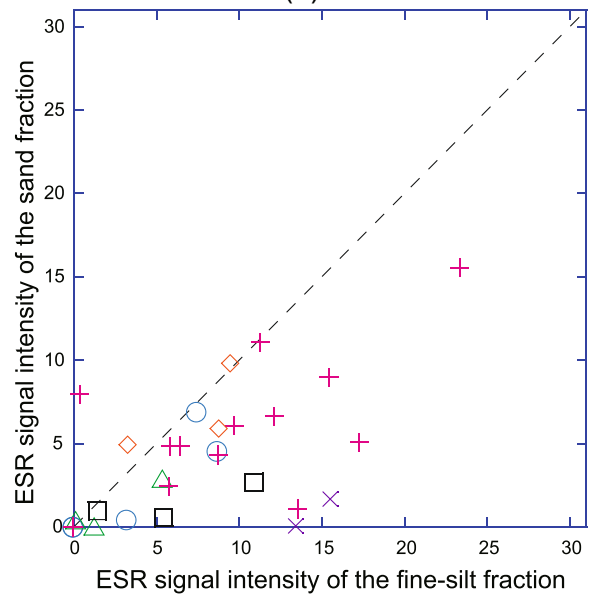

(b)

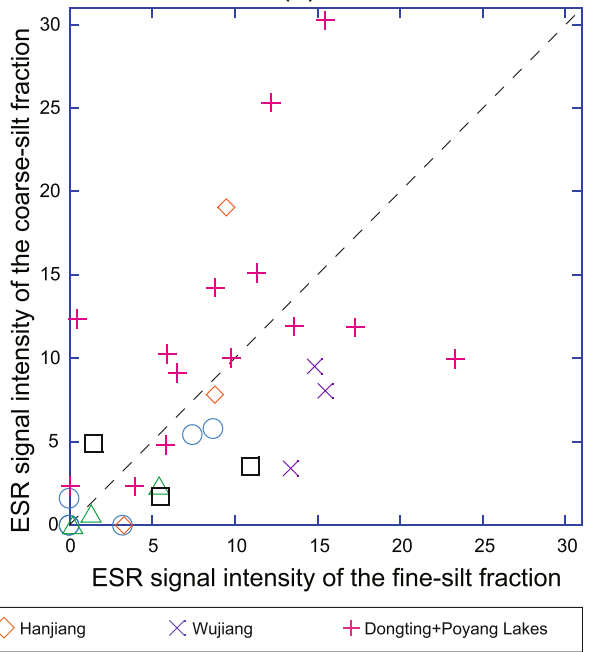

Fig. 7 Comparison of electron spin resonance (ESR) signal intensities among the three size fractions of riverbed samples collected in this study. a Fine-silt versus sand fractions. b Fine-silt versus coarse-silt fractions
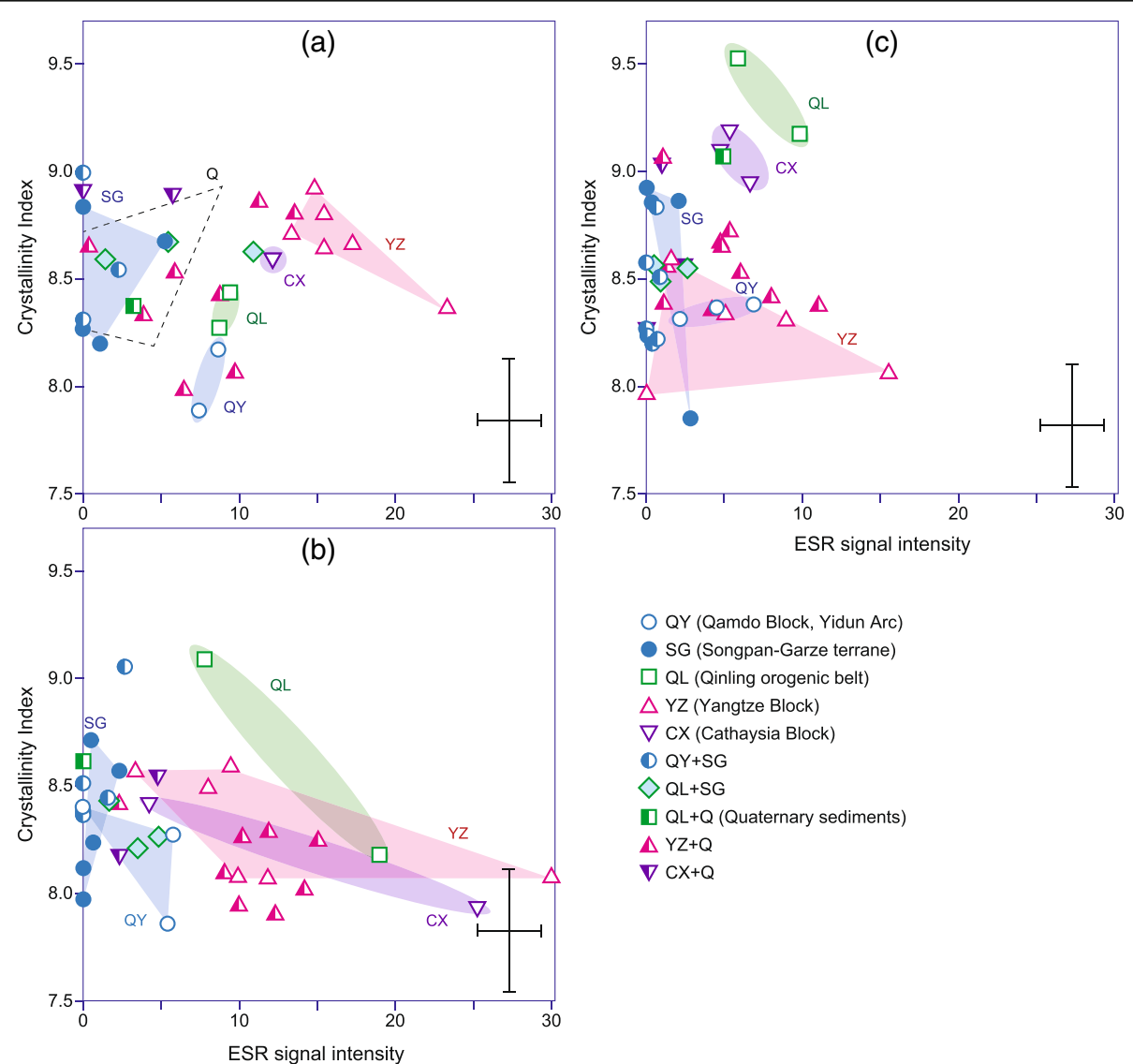

O QY (Qamdo Block, Yidun Arc)

SG (Songpan-Garze terrane)

$\square \mathrm{QL}$ (Qinling orogenic belt)

$\triangle Y Z$ (Yangtze Block)

$\nabla \mathrm{CX}$ (Cathaysia Block)

D $Q Y+S G$

$\diamond \mathrm{QL}+\mathrm{SG}$

$\square \mathrm{QL}+\mathrm{Q}$ (Quaternary sediments)

$\triangle Y Z+Q$

$\nabla C X+Q$

Fig. 8 An ESR-Cl plot for riverbed sediments from each of the geological blocks in the Yangtze drainage basin. a Fine-silt (4-16 $\mu \mathrm{m})$ fraction. b Coarse-silt $(16-63 \mu \mathrm{m})$ fraction. c Sand (>63 $\mu \mathrm{m})$ fraction. QY Qamdo Block and Yidun Arc, SG Songpan-Garze terrane, QL Qinling orogenic belt, YZ Yangtze Block, CX Cathaysia Block, Q Quaternary sediments in the middle-lower parts of the mainstream 
both the SG and the QL, although the basement of the Sichuan Basin belongs to the YZ (Wang et al. 2013; Luo et al. 2014).

The ESR signal intensity increases with increasing age of the host rock (Toyoda and Naruse 2002). According to Toyoda (1992), the Cenozoic granites show $\mathrm{E}_{1}{ }^{\prime}$ center densities of $<1.3 \times 10^{15}$ spins/g while the Proterozoic granites show $\mathrm{E}_{1}{ }^{\prime}$ center densities of $>1.3 \times 10^{16} \mathrm{spins} / \mathrm{g}$. Because the units of ESR signal intensity are defined as $1.3 \times 10^{15} \mathrm{spins} / \mathrm{g}$, the ESR signal intensities of the Cenozoic rocks are less than $\sim 1$, those of Mesozoic rocks are from $\sim 1$ to $\sim 3$, those of upper Paleozoic rocks are from $\sim 3$ to $\sim 10$, and those of Proterozoic rocks are greater than $\sim 10$ (Toyoda and Hattori 2000). Based on these general patterns, we categorized ESR signal intensities into three classes: low $(<3$; roughly corresponding to Cenozoic and Mesozoic rocks), medium (3-10; roughly corresponding to Paleozoic rocks), and high (>10; roughly corresponding to Proterozoic rocks). However, we recognize the need to take into account the rock type dependency of the ESR signal intensity caused by differences in radionuclide activity in different rocks.

We also categorized CI values into three classes based on the 1st quartile (8.2) and 3rd quartile (8.7) of all fractions: low $\mathrm{CI}$ values are $<8.2$, medium $\mathrm{CI}$ values are from 8.2 to 8.7 , and high $\mathrm{CI}$ values are $>8.7$.

\section{Relationship between ESR signal intensity and $\mathrm{Cl}$ values of the fine-silt (4-16 $\mu \mathrm{m})$ fraction of sediments in tributaries and the geological blocks in their drainage basins}

Quartz grains in riverbed sediments can be a mixture of different source rocks within a given drainage basin, and thus, ESR signal intensity and CI values of the riverbed sediments do not necessarily represent those of a single geological block or source rock. However, in the discussion that follows, we assume that the range of ESR signal intensity and CI values in riverbed samples collected from a given geological block represent the minimum range of values in the various source rocks within that block.

Figure 8a shows ESR signal intensity and CI values of quartz in the fine-silt fraction of river sediments, with symbols indicating the geological block(s) exposed in the drainage basin of the sample. As shown in the "Results and Discussion" section, the fine-silt fraction could well represent the composition of SPM in the Yangtze River. Here, we discuss the features of ESR signal intensity and CI values in the fine-silt fraction as proxies for the SPM provenance.

Songpan-Garze terrane Samples derived from SG exhibit low to medium ESR signal intensities (0.0-5.3) and medium CI values (8.2-8.8). The SG is composed mainly of Mesozoic shallow-marine sediments, including sandstones and carbonates (Enkelmann et al. 2007; Liu et al. 2011), which is consistent with low ESR signal intensities.

Qamdo Block and Yidun Arc Samples derived from QY exhibit medium ESR signal intensities $(\sim 8)$ and low CI values (7.8-8.2). The Yidun Arc, which occupies a large part of QY, is composed of Paleozoic melange and Permian-Tertiary shales and sandstones that yield upper Paleozoic to Proterozoic zircon ages (Wang et al. 2000; Reid et al. 2005b; Deng et al. 2014); these ages are consistent with medium ESR signal intensities of $\sim 8$.

Qinling orogenic belt Samples derived from QL exhibit medium ESR signal intensities ( 9) and medium CI values ( 8.4). The QL is composed mainly of Neoproterozoic turbidites, phyllite, and sandstone; Silurian slate and sandstone; Devonian schist; and Triassic granite (Meng and Zhang 2000; Dong et al. 2011; Dong and Santosh 2016). Because the QL block in the Yangtze drainage basin was not metamorphosed after the Neoproterozoic (Dong et al. 2011; Dong and Santosh 2016), the rocks in QL are assumed to yield quartz showing an upper Paleozoic-Proterozoic age when quartz grains were originally formed. This age is consistent with ESR signal intensity of $\sim 9$.

Yangtze Block Samples derived from YZ exhibit high ESR signal intensities (12-23) and medium to high CI values (8.3-9.0). The YZ is composed mainly of Proterozoic basement that experienced low-grade metamorphism before the Neoproterozoic and lower Paleozoic sandstones, mudstones, and carbonates (Chen and Jahn 1998; Wang et al. 2010, 2013). As the lower Paleozoic sandstones in YZ are assumed to be derived from the Proterozoic basement and/or granites in the Cathaysia Block (Wang et al. 2010), both Proterozoic basement and Paleozoic clastic rocks seem to have a Proterozoic source rock age. This inference is consistent with the high ESR signal intensity values observed in the block $(>10)$.

Cathaysia Block A sample from CX shows a high ESR signal intensity of 12.2 and a medium CI value of 8.6. The CX is composed mainly of Proterozoic basement, lower Paleozoic siliciclastics, and Cretaceous red-colored sandstones (Wang et al. 2007a, 2013). Cretaceous sandstones were probably derived from the $\mathrm{YZ}$ basement, which are Proterozoic in age (as mentioned above), which is consistent with the observed ESR signal intensity of $>10$.

Quaternary sediments in the middle to lower parts These types of sediment are thought to have been transported by the Yangtze mainstream (Yin et al. 2007; Dai and Lu 2010). Therefore, the Quaternary (Q) sediments in the middle and lower parts could be represented by 
riverbed sediments deposited in the middle part of the mainstream, where ESR signal intensities are low $(\sim 3)$ and $\mathrm{CI}$ values are moderate $(\sim 8.4)$.

Mixing of various source rocks Samples derived from QY + SG (from the Jinshajiang) show low to medium ESR signal intensities (0.0-3.2) and medium to high CI values (8.3-9.0), which are close to the values observed in SG. Because $80 \%$ of the sediments discharged from the Jinshajiang are derived from the SG region in the lower part of the Jinshajiang (Liu et al. 2011), it is reasonable that ESR signal intensity and CI values of samples derived from QY + SG are strongly affected by SG values. Samples derived from QL + SG (from the Jialingjiang) show a wide range of ESR signal intensities (1.4$10.9)$ and medium CI values ( 8.6). These values lie between those of SG and QL, supporting the idea that the sediments of QL + SG are mixtures of sediments derived from QL and SG. A sample derived from QL + Q (from the Hanjiang) shows a medium ESR signal intensity of 3.3 and a medium CI value of 8.4. Samples derived from $\mathrm{YZ}+\mathrm{Q}$ obtained from the Dongting Lake tributaries show low to high ESR signal intensities of 0-14. Samples derived from $\mathrm{CX}+\mathrm{Q}$ obtained in the Poyang Lake tributaries show low to medium ESR signal intensities of 0-6. Because sediments of $Q$ have similar ESR signal intensity and $\mathrm{CI}$ values to samples from the middle part of the mainstream, the ESR signal intensity and CI values of $\mathrm{QL}+\mathrm{Q}, \mathrm{YZ}+\mathrm{Q}$, and $\mathrm{CX}+\mathrm{Q}$ lie along the mixing lines between $\mathrm{QL}$ and $\mathrm{Q}, \mathrm{YZ}$ and $\mathrm{Q}$, and $\mathrm{CX}$ and $\mathrm{Q}$, respectively. Therefore, the ESR and CI values of the samples can be explained by a mixing of the values of individual geological blocks.

In summary, our data demonstrate that the ESR signal intensity of the fine-silt fraction $(4-16 \mu \mathrm{m})$ extracted from riverbed samples collected on each geological block are consistent with the ages of the dominant rock types in that block.

\section{Differences in ESR signal intensity and $\mathrm{Cl}$ values among the three size fractions representing each geological block}

Figure 8 shows clear differences in ESR signal intensity and $\mathrm{CI}$ values among the three sediment size fractions, with the nature of the differences depending on the composition of the geological blocks. Thus, in this subsection, we discuss the differences in ESR signal intensity and CI values among the three size fractions representing each geological block.

Qamdo Block and Yidun Arc Compared with the finesilt fraction, the sand fraction of samples from QY shows lower or similar ESR signal intensities (2.2-6.9) and slightly higher CI values ( 8.3), while the coarse-silt fraction shows values intermediate between those of the sand and fine-silt fractions (Fig. 8a-c). Clastic sediments from QY yield Proterozoic to upper Paleozoic zircon ages (Wang et al. 2000; Deng et al. 2014) that are consistent with the medium ESR signal intensities observed in the fine-silt fraction. On the other hand, coarse clastic sediments or Mesozoic granite-granodiorite may have contributed to low ESR signal intensities in the sand fraction, although it is difficult to specify the source rock of each fraction due to the structural complexity of QY (Reid et al. 2005a).

Songpan-Garze terrane The coarse-silt fraction of samples derived from SG shows low ESR signal intensities (0.0-2.4) and low to medium CI values (8.0-8.7) as compared with the sand fraction, which also shows low ESR signal intensities (0.0-2.9) but a wide range of CI values (7.8-8.9) (Fig. 8b, c). As the three size fractions derived from SG show similar ESR signal intensity and $\mathrm{CI}$ values, they are inferred to be derived from the same rocks.

Qinling orogenic belt Compared with the fine-silt fraction, the coarse-silt fraction of samples derived from QL shows similar to higher ESR signal intensities (7.8-19.3) and lower to similar CI values (7.8-8.4), whereas the sand fraction shows similar to higher ESR signal intensities (5.9-9.8) and higher CI values (9.2-9.5) (Fig. 8a-c). The high $\mathrm{CI}$ values of the sand and coarse-silt fractions suggest that Neoproterozoic and Triassic granite in the South Qinling area or Quaternary loess in the Hanjiang drainage basin contributed to the coarse-silt and sand fractions (Meng and Zhang 2000; Dong et al. 2011; Zhang et al. 2012; Dong and Santosh 2016).

Yangtze Block Compared with the fine-silt fraction, the sand and coarse-silt fractions of samples derived from YZ show lower to similar ESR signal intensities (3.430.0) and lower to similar $C I$ values (8.1-8.6) as (Fig. $8 \mathrm{a}-\mathrm{c}$ ). Silicate rocks of $\mathrm{YZ}$ are dominantly composed of Proterozoic basement that was metamorphosed during the Neoproterozoic, lower Paleozoic slate and sandstone, Mesozoic sandstone, and Mesozoic granite (Wang et al. 2013). Based on the high ESR signal intensity and medium to high CI values, the fine-silt fraction seems to have been derived from the Proterozoic basement. In the YZ area, lower Paleozoic sandstones seem to be derived from the Proterozoic basement of the Cathaysia Block (CX) and they show high ESR signal intensity and low CI values, while Mesozoic granites show low ESR signal intensity and high CI values (Wang et al. 2010, 2013). Therefore, the lower ESR signal intensities and CI values of the coarse-silt and sand fractions than the fine-silt fraction in YZ could be explained by contributions from Mesozoic granites and Paleozoic sandstones. 
Cathaysia Block The sand fraction of samples derived from CX shows lower ESR signal intensities (4.8-6.6) and higher CI values (9.0-9.2) than those of the fine-silt fraction. The presence of granites that intermittently intruded into CX during the Neoproterozoic-Jurassic (Wang et al. 2013) might explain the higher CI values in the coarser sediment fractions.

We suggested that detrital quartz grains of different sizes are derived from different sources. To test this possible explanation for differences in ESR signal intensity and $\mathrm{CI}$ values, it is necessary to perform an ESR analysis of quartz, combined with petrological observations of quartz grains in all varieties of potential source rocks in each geological block.

\section{Classification of tributaries based on ESR signal intensity and $\mathrm{Cl}$ values of the fine-silt fraction of sediments dis- charged from each tributary}

We examine the relationship between ESR signal intensity and CI values of the fine-silt fraction of sediments discharged from each tributary, in terms of the geological block(s) exposed in each drainage basin.
The major tributaries can be categorized into four groups based on the distribution of the geological block(s) in each drainage (Fig. 9): (1) the upper part of the Jinshajiang, including the Jinshajiang above Big Bend; (2) western tributaries, including the lower parts of the Jinshajiang, Yalongjiang, and Minjiang; (3) northeastern tributaries, including the Jialingjiang and Hanjiang; and (4) southeastern tributaries, including the Wujiang, Dongting Lake, and Poyang Lake tributaries.

The upper part of the Jinshajiang is characterized by medium ESR signal intensities (7.5-8.7) and low CI values (7.9-8.2), reflecting the presence of clastic sediments with upper Paleozoic to Proterozoic ages. The characteristics of this group are nearly equivalent to those of the QY. The western tributaries are characterized by low ESR values (0.0-3.2) and a wide range of CI values (7.8-9.0), reflecting the presence of Mesozoic shallow-marine sediments in the basins, including sandstone and carbonates. This group is characterized by a dominant contribution from SG. The northeastern tributaries are characterized by a wide range of ESR values (1.5-11.0) and medium CI values (8.3-8.7), reflecting

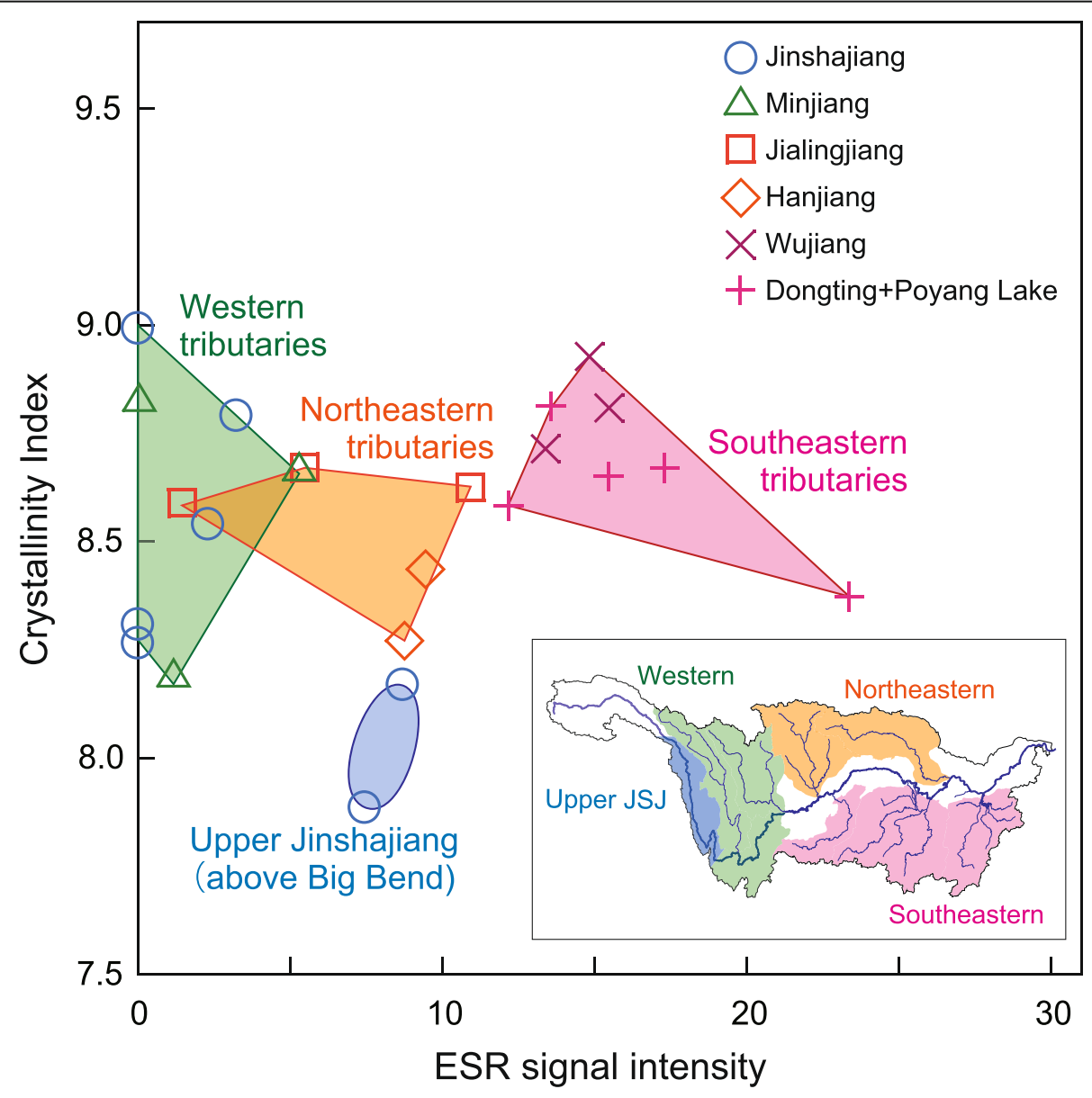

Fig. 9 An ESR-Cl plot of quartz in the fine-silt fraction of riverbed samples from the major tributaries 
the presence of both Mesozoic shallow-marine sediments derived from SG and upper Paleozoic clastic rocks and Proterozoic basement from QL. The southeastern tributaries are characterized by high ESR values (11.3-23.4) and low-medium CI values (8.4-8.9), representing the presence of Proterozoic basement in $\mathrm{YZ}$ and CX. Because contributions of sediment from the lower part of the Yangtze are negligible, they are not discussed here.

\section{Predicted changes in the ESR signal intensity in sediments of the Yangtze mainstream below its junction with major tributaries}

We calculated the theoretical (predicted) ESR signal intensity of quartz in the fine-silt fraction of the sediments in the mainstream immediately below junctions with major tributaries by applying a simple mixing ratio approach, to examine whether ESR signal intensity values of sediments reflect mixing ratios of sediments discharged from the mainstream and tributary immediately above the junctions. We used the sediment (SPM) budget at the junctions as determined from modern (post-TGD) observational data (Fig. 4), in addition to the analyzed ESR signal intensities of quartz in the fine-silt fraction of the sediments from each tributary and from sites along the mainstream immediately above the junctions, as end-members for determining mixing ratios and for calculating the predicted ESR signal intensities of quartz downstream from the junctions. The results are compared with the analyzed ESR signal intensities for the fine-silt fraction of samples collected from mainstream sites immediately below the junctions.

In our calculations, we used ESR signal intensity and CI values of quartz in the fine-silt fractions of the sediments from each tributary, as listed in Table 1. As mentioned above, the ESR signal intensity and CI values of the sediments collected at Yibin, at the outlet of the Jinshajiang, appear to be strongly affected by sediments supplied from the lower part of the Jinshajiang. Therefore, in the calculations of the average ESR signal intensity and $\mathrm{CI}$ values of the sediments from the Jinshajiang, we used only samples from the lower part of the Jinshajiang. For the Hanjiang, Dongting Lake, and Poyang Lake drainages, we used samples collected from the middle parts of the drainages, as samples from the lower parts and along the shorelines of lakes are likely contaminated by sediments from the mainstream during periods of flood.

The ESR signal intensity and CI values for the fine-silt fraction of quartz in sediments from below the junctions of the mainstream and tributaries were calculated as the weighted averages of the values in sediments from immediately above the junction in the mainstream and the tributary, respectively. In the calculations, we assume that sediments from the mainstream and the tributary are sufficiently mixed below the junction to apply the simple mixing ratio approach. Underlined variables in the following equations indicate observed or analyzed data.

First, we calculated the fine-silt fraction of the quartz load from the mainstream $\left(Q_{\text {main }} ; \mathrm{Mt} /\right.$ year $)$ and a tributary $\left(Q_{\text {tri }} ; M t /\right.$ year $)$ as

$$
\begin{aligned}
& Q_{\text {main(aj) }}=\underline{S_{\text {main(aj) }}} \times \underline{f_{\text {fs }}} \times \underline{C_{\text {main(aj) }}} \text {, and } \\
& Q_{\text {tri }}=\underline{S_{\text {tri }}} \times \underline{f_{\text {fs }}} \times \underline{C_{\text {tri }}},
\end{aligned}
$$

where $S_{\text {main(ai) }}$ is the observed sediment load in the mainstream just above the junction with the tributary of interest (Mt/year), $f_{\mathrm{fs}}$ is the proportion of the fine-silt fraction with respect to the total SPM, and $C_{\text {main(ai) }}$ is the analyzed quartz content in the fine-silt fraction of the sediments collected from a site on the mainstream just above the junction with the tributary of interest. Similarly, $S_{\text {tri }}$ is the observed sediment load from the tributary of interest (Mt/year) and $C_{\text {tri }}$ is the analyzed quartz content in the fine-silt fraction of the sediments collected from the tributary of interest. The average annual sediment loads from the mainstream and each tributary are shown in Fig. 4; all data were collected after the start of TGD operations.

\begin{tabular}{|c|c|c|c|c|c|c|}
\hline \multirow[t]{2}{*}{ Tributary } & \multicolumn{3}{|c|}{ ESR signal intensity } & \multicolumn{3}{|l|}{$\mathrm{Cl}$ values } \\
\hline & Minimum & Maximum & Average & Minimum & Maximum & Average \\
\hline Jinshajiang & 0.00 & 3.23 & 1.39 & 8.31 & 8.79 & 8.66 \\
\hline Minjiang & 0.00 & 5.26 & 2.14 & 8.83 & 8.67 & 8.57 \\
\hline Jialingjiang & 1.46 & 10.9 & 5.96 & 8.59 & 8.67 & 8.63 \\
\hline Wujiang & 13.4 & 15.5 & 14.6 & 8.71 & 8.81 & 8.81 \\
\hline Dongting Lake & 11.3 & 23.4 & 15.9 & 8.87 & 8.68 & 8.37 \\
\hline Hanjiang & 8.76 & 9.45 & 9.10 & 8.27 & 8.44 & 8.35 \\
\hline Poyang Lake & 12.2 & 12.2 & 12.2 & 8.58 & 8.58 & 8.58 \\
\hline
\end{tabular}

Table 1 Ranges of ESR and Cl values for each tributary in the fine-silt fraction (4-16 $\mu \mathrm{m})$ 
As the grain size distribution of SPM changes seasonally and in different parts of the Yangtze (Mao et al. 2010), the value of $f_{\mathrm{fs}}$ could also change depending on the season and the part of interest. We estimated the value of $f_{\mathrm{fs}}$ as follows.

Regarding seasonal variations, we assumed that summertime values of $f_{\mathrm{fs}}$ provide a reasonable representation of the annual average, as roughly $90 \%$ of the annual sediment yield from the Yangtze River occurs during the summer ( $\mathrm{Hu}$ et al. 2011). To evaluate the value of $f_{\mathrm{fs}}$, we analyzed the grain size distribution of SPM in samples taken at Yichang and Nanjing during the same season and year as samples collected for our riverbed sampling. The values of $f_{\mathrm{fs}}$ at Yichang and Nanjing were 32 and $34 \%$, respectively. These ratios of the fine-silt fraction in SPM are consistent with those at Yichang and Datong, respectively, as determined by Gao et al. (2015). Because the values of $f_{\text {fs }}$ at Yichang and Nanjing are similar, we adopted the average value of $f_{\mathrm{fs}}$ obtained at Yichang and Nanjing, of 33\%, as the value of $f_{\mathrm{fs}}$ in Eqs. (1) and (2).

Next, we calculated the quartz load of the fine-silt fraction of the mainstream below the junction $\left(Q_{\text {main(bj) }}\right.$; Mt/year) as

$$
Q_{\text {main }(\mathrm{bj})}=Q_{\text {main }(\mathrm{aj})}+Q_{\mathrm{tri}}
$$

and then calculated the contribution ratio of the finesilt-sized quartz load of the mainstream above the junction to that of the mainstream below the junction $\left(r_{\mathrm{Q} \text {,main }}\right)$, as well as the contribution ratio of the fine-siltsized quartz load from the tributary of interest to that of the mainstream below the junction $\left(r_{\mathrm{Qtri}}\right)$, using Eqs. (4) and (5), respectively:

$$
\begin{aligned}
& r_{\mathrm{Q}, \text { main }}=Q_{\text {main }(\mathrm{aj})} / Q_{\text {main }(\mathrm{bj})}, \text { and } \\
& r_{\mathrm{Q}, \text { tri }}=Q_{\text {tri }} / Q_{\text {main }(\mathrm{bj})} .
\end{aligned}
$$

Finally, we calculated the ESR signal intensity of quartz in the fine-silt fraction of the sediment from the mainstream below the junction $\left(\mathrm{ESR}_{\text {main(bj) }}\right)$ as

$$
\mathrm{ESR}_{\text {main(bj) }}=\underline{\mathrm{ESR}_{\text {main }(\mathrm{aj})}} \times r_{\mathrm{Q}, \text { main }}+\underline{\mathrm{ESR}_{\text {tri }}} \times r_{\mathrm{Q}, \mathrm{tri}},
$$

where $\mathrm{ESR}_{\text {main(aj) }}$ is the analyzed ESR signal intensity of quartz in the fine-silt fraction of the sediments from the mainstream above the junction and $\mathrm{ESR}_{\text {tri }}$ is that in the fine-silt fraction of the sediments from the tributary. The value of $\underline{E S R}_{\text {tri }}$ is assumed to vary between the minimum and maximum ESR signal intensities listed in Table 1.

Using Eqs. (1) to (6), the ESR signal intensities below each junction were predicted at the mainstream junctions with the Minjiang, Jialingjiang, Wujiang, and Poyang Lake. The junctions with the Yalongjiang and Dongting Lake were excluded from the analysis, as riverbed sediments in the mainstream are lacking above the junctions with these tributaries. The junction with the
Hanjiang was also excluded, as the sample collected from the mainstream above the junction showed an unusual ESR signal intensity of 0.0. Because this sample was collected from meter-scale bedded sediments exposed above the river surface, this sample could represent past sediments deposited during a flood and could thus show a low ESR signal intensity reflecting a specific source area, such as the SG block.

Results of the calculations are listed in Table 2. Figure 10 shows the correlation between the predicted and analyzed ESR signal intensities in the mainstream below the junctions with each major tributary. The analyzed ESR signal intensities agree well with the predicted values (within the reproducibility of the analyzed ESR values; \pm 2.2 ) below the junctions with the Minjiang, Jialingjiang, and Poyang Lake tributaries, indicating that the analyzed ESR signal intensity properly reflects the relative sediment contributions from the mainstream and the tributary from above the junctions.

On the other hand, the analyzed ESR signal intensity below the junction with the Wujiang is larger than predicted (and beyond the analytical error). At this junction, the sampling site on the mainstream was located $40 \mathrm{~km}$ below the Wujiang (LYZ120212-01a; Additional file 1), and it is possible that a local river, the Longhe, which drains into the mainstream from the same side as the Wujiang at a location less than $1 \mathrm{~km}$ above the sampling site, influenced the results. As the geology of the Longhe drainage basin is similar to that of the Wujiang, it is likely that detrital material from the Longhe is also characterized by high ESR values (as are the Wujiang sediments). This material may have affected the ESR signal intensity values of sample LYZ120212-01a, on account of the proximity of the Longhe to the sampling site. Thus, the analyzed ESR signal intensity of sample LYZ120212-01a is likely to be higher than predicted because of the effects of the high ESR signal intensities of sediments from the Longhe.

\section{Estimated ESR signal intensity and $\mathrm{Cl}$ values of quartz in the fine-silt fraction of modern sediments along the main- stream of the Yangtze}

As discussed above, the analyzed ESR signal intensities of samples collected from sites below junctions with

Table 2 Predicted and analyzed ESR signal intensity of the mainstream below the junction with tributaries

\begin{tabular}{lcc}
\hline Tributary & \multicolumn{2}{c}{ ESR signal intensity } \\
\cline { 2 - 3 } & Predicted & Analyzed \\
\hline Minjiang & 1.34 & 1.49 \\
Jialingjiang & 2.23 & 3.88 \\
Wujiang & 4.27 & 7.92 \\
Poyang Lake & 5.19 & 3.74 \\
\hline
\end{tabular}




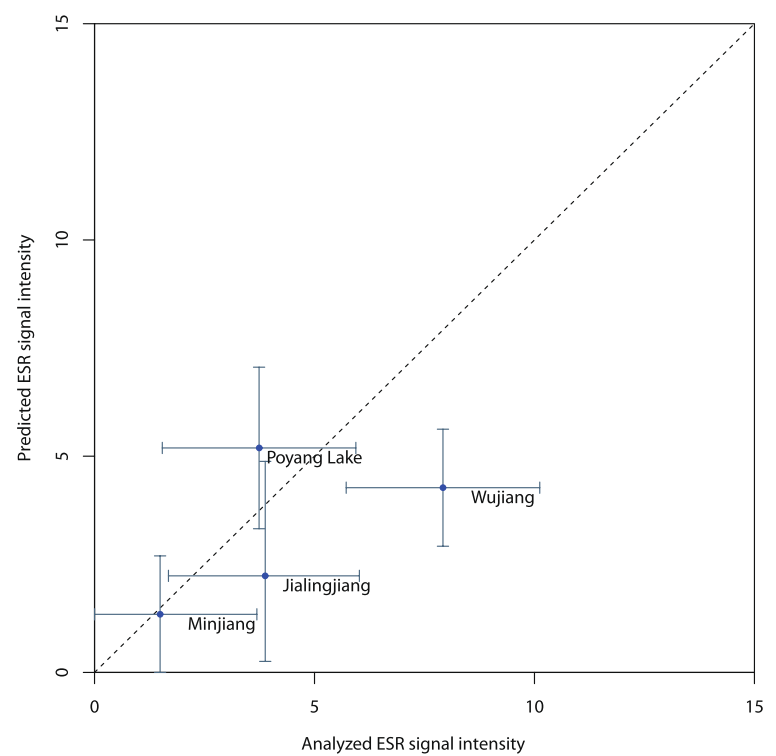

Fig. 10 Predicted and analyzed ESR signal intensities of quartz below junctions with major tributaries

major tributaries reflect the relative contributions of sediments from the mainstream and the tributary above the junction. Using such an approach, we can also estimate changes in ESR signal intensities of the fine-silt fraction of sediments along the mainstream from the uppermost part to the rivermouth. This approach could further validate whether ESR signal intensities in the fine-silt fraction of the sediments at the rivermouth can be used to predict sediment budgets in the Yangtze drainage basin in the past.

The following assumptions were made in performing the calculations which predict the ESR signal intensity along the mainstream: (a) sediments from the mainstream and tributaries are sufficiently mixed below junctions, (b) sediment input from small tributaries is negligible, and (c) quartz contents do not change during transport as SPM along the mainstream.

We first performed calculations for the junction of the Jinshajiang and Minjiang and predicted the ESR signal intensity below the junction using Eqs. (1) to (6) (see above). Next, we predicted the ESR signal intensity at the junction of the Yangtze mainstream and the Jialingjiang using the same equations; however, the ESR signal intensity of the mainstream above the junction was assumed to be the same as the predicted value below the previous junction (i.e., the junction of the Jinshajiang and Minjiang). Then, similar calculations were repeated at every junction with a major tributary (i.e., at the junctions with the Wujiang, Dongting Lake, Hanjiang, and Poyang Lake tributaries).

The amount of eroded sediments on the mainstream between Yichang and Hankou and between Hankou and
Datong were assumed to be 47 and $17 \mathrm{Mt} /$ year, respectively (Fig. 4). In our calculations, erosion between Yichang and Hankou was split equally into two parts: from Yichang to Yueyang (outlet of Dongting Lake) and from Yueyang to Hankou. The ESR signal intensity and $\mathrm{CI}$ values for the sediments eroded between Yichang and Yueyang, Yueyang and Hankou, and Hankou and Datong were assumed to be the same as those of sediments passing through Yichang, Yueyang, and Hankou before TGD construction, respectively, as the sediments were deposited along the middle to lower part of the mainstream before TGD construction (Fig. 3). The ESR signal intensity and CI values at Yichang, Yueyang, and Hankou prior to the TGD were estimated using the same calculations (Eqs. (1) to (6)) and the sediment budget shown in Fig. 3.

It is assumed that $80.3 \%$ of the sediment flowing into the TGD area between the junction of the mainstream and the Wujiang and the dam body is trapped in the TGD. Thus, we have

$$
Q_{\mathrm{TGD}, \text { output }}=(1-0.803) \times Q_{\mathrm{TGD}, \text { input }},
$$

where $Q_{\mathrm{TGD} \text {,input }}$ is the quartz load of the mainstream below the junction with the Wujiang and $Q_{\mathrm{TGD} \text {,output }}$ the quartz load of the mainstream below the TGD.

Similar to Eq. (7), we assumed that $10.0 \%$ of the sediment flowing into Dongting Lake is deposited within Dongting Lake, based on the sediment budget presented in Fig. 4:

$$
Q_{\text {DTL }, \text { output }}=0.9 \times Q_{\text {DTL,input }} .
$$

The calculation in Eqs. (1)-(6) was repeated at every junction from the upper part to the lower part along the mainstream (Table 3; Fig. 11). The results of these calculations using averaged ESR signal intensity and $\mathrm{CI}$ values are listed in Table 3 as "predicted averages" of the ESR signal intensity and $\mathrm{CI}$ values for each tributary (data in Table 1). Similarly, results of the calculations using maximum and minimum values of the ESR signal intensity and CI are listed in Table 3 as "predicted maximum" and "predicted minimum" values for each tributary (see Table 1). As described above, the sediments collected from the site below the junction with the Wujiang and the site above the junction with the Hanjiang are assumed to be exceptional. Thus, the characteristics of these two sediments are omitted from Table 3 and Fig. 11.

If the sediment budget shown in Fig. 4 properly reflects the volume of sediments transported along the mainstream, then we should expect that predicted average ESR signal intensity and CI values after mixing will be within the analytical error of the analyzed ESR signal intensities of the riverbed sediments. Figure 11 shows that the predicted average ESR signal intensities (solid circles) 
Table 3 Predicted and analyzed ESR and CI values along the mainstream in the fine-silt fraction (4-16 $\mu \mathrm{m})$

\begin{tabular}{|c|c|c|c|c|c|c|c|c|}
\hline \multirow[t]{3}{*}{ Location } & \multicolumn{6}{|l|}{ Predicted } & \multicolumn{2}{|c|}{ Analyzed } \\
\hline & \multicolumn{3}{|c|}{ ESR signal intensity } & \multicolumn{3}{|l|}{$\mathrm{Cl}$ values } & \multirow[t]{2}{*}{ ESR } & \multirow[t]{2}{*}{$\mathrm{Cl}$} \\
\hline & Minimum & Maximum & Average & Minimum & Maximum & Average & & \\
\hline Above MJ (Jinshajiang) & 0.0 & 3.2 & 1.8 & 8.3 & 8.8 & 8.7 & 1.9 & 8.7 \\
\hline Below MJ/above Jレ & 0.0 & 3.5 & 1.9 & 8.3 & 8.8 & 8.6 & 1.5 & 7.9 \\
\hline Below JLJ/above WJ & 0.3 & 4.8 & 2.6 & 8.4 & 8.7 & 8.6 & 3.9 & 8.6 \\
\hline Below WJ/TGD input & 0.9 & 5.3 & 3.1 & 8.4 & 8.8 & 8.7 & - & - \\
\hline Upper area of TGD & 0.9 & 5.3 & 3.1 & 8.4 & 8.8 & 8.7 & 4.2 & 8.7 \\
\hline TGD output & 0.9 & 5.3 & 3.1 & 8.4 & 8.8 & 8.7 & 1.8 & 8.8 \\
\hline Below DTL & 2.8 & 9.1 & 5.6 & 8.5 & 8.7 & 8.7 & 9.1 & 8.7 \\
\hline Above HJ & 2.6 & 8.9 & 5.3 & 8.5 & 8.7 & 8.7 & - & - \\
\hline Below HJ & 3.1 & 8.9 & 5.6 & 8.5 & 8.7 & 8.7 & 7.7 & 8.7 \\
\hline Above PYL & 3.0 & 9.0 & 5.6 & 8.5 & 8.7 & 8.6 & 4.0 & 8.2 \\
\hline Below PYL & 4.0 & 9.7 & 6.5 & 8.5 & 8.7 & 8.6 & 3.8 & 8.7 \\
\hline Rivermouth & 4.0 & 9.7 & 6.5 & 8.5 & 8.7 & 8.6 & 4.4 & 8.5 \\
\hline
\end{tabular}

Note: MJ Minjiang, JL Jialingjiang, WJ Wujiang, TGD Three Gorges Dam, DTL Dongting Lake, HJ Hanjiang, PYL Poyang Lake

agree well with the analyzed ESR signal intensities (within the reproducibility of the ESR analysis of \pm 2.2 ; open circles with errors) at 8 out of 10 locations, indicating that the predicted average ESR signal intensities can be used to predict the ESR signal intensities of the riverbed sediments.

Two predicted ESR signal intensity values, below the junctions with the Dongting Lake and Poyang Lake tributaries, are beyond the acceptable error range of the analyzed values. Lane et al. (2008) reported that several to tens of kilometers of distance are necessary for river waters to completely mix after two rivers merge. Sampling sites on the mainstream below the junctions with Dongting Lake, which show higher than predicted ESR values, are located on the tributary-merging side of the mainstream $8 \mathrm{~km}$ below the junction. As previously described, the ESR signal intensities for sediments from Dongting Lake are characterized by values that are higher than those of the mainstream. Thus, it is likely that samples below the junction with Dongting Lake are influenced by sediments derived from the lake, which show ESR values higher than those of the

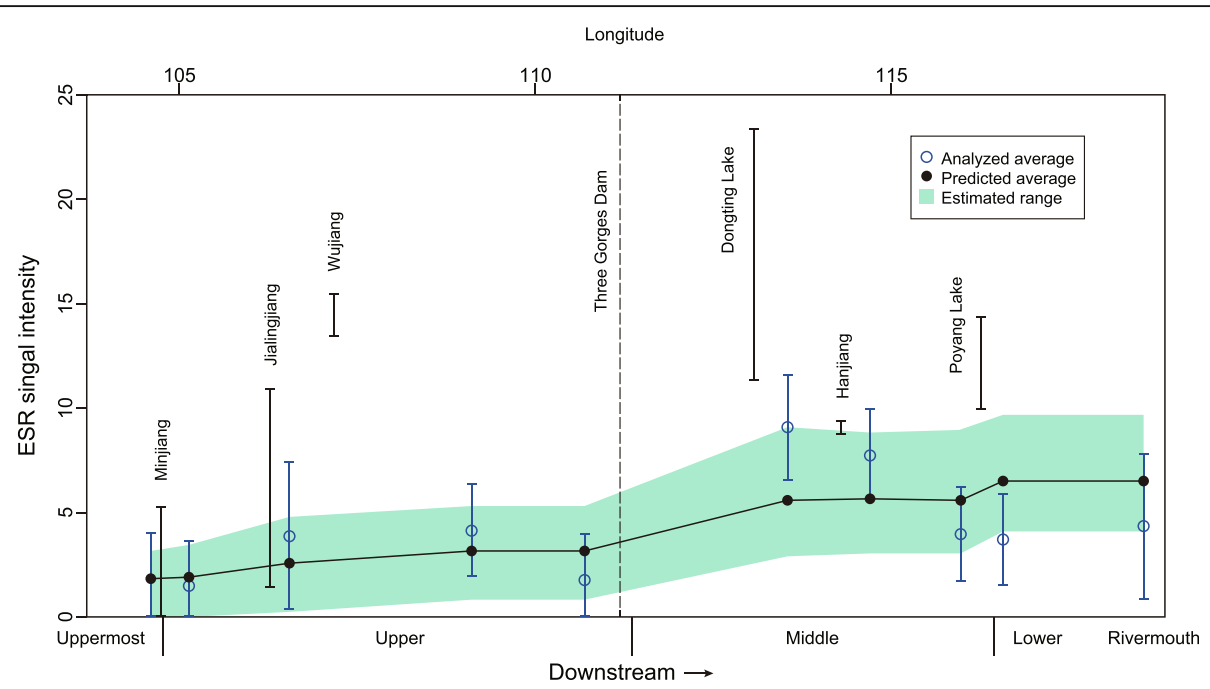

Fig. 11 Comparison of predicted and analyzed ESR signal intensities of quartz in the fine-silt fraction along the mainstream. Green area indicates the range of predicted ESR signal intensities. Solid circles indicate the averages of predicted ESR signal intensities along the mainstream. The green-shaded area indicates the ranges of predicted ESR signal intensities. The blue open circles indicate analyzed ESR signal intensities of the fine-silt fractions at sites along the mainstream. Samples that are identified as exceptions in Fig. 10 are omitted from this figure, namely a sample collected below the junction with the Wujiang and a sample collected above the junction with the Hanjiang (see text for details) 
mainstream above the junction. This problem could be resolved by taking samples from sites at sufficient distances from the junctions with tributaries.

On the other hand, the analyzed ESR signal intensities in the middle to lower parts tend to be lower than predicted values. These lower values could be the result of erosion along the middle to lower parts of the mainstream. For example, the meter-scale bedded sediments above the junction with the Hanjiang are readily eroded and show ESR signal intensity values of 0.0; such sediments could strongly modify the signal in the SPM fraction in the mainstream. Our present predictions of ESR signal intensity along the mainstream assume that the ESR signal intensity of eroded sediments in the middle to lower parts corresponds to the average ESR signal intensity of $\sim 4$ that was observed at Yichang or Yueyang. However, if we assume that all eroded sediments have ESR signal intensities of 0 , the predicted average ESR signal intensity would be 4.6 , which is very close to the analyzed values. Thus, the effects of eroded sediments on the ESR signal intensity values observed in the middle to lower parts could explain the departures between predicted and analyzed ESR values in these sections of the mainstream.

He et al. (2015), in a study of the geochemistry of riverbed sediments in the Yangtze basin, reported that $\mathrm{Nd}$ and $\mathrm{Sr}$ isotope ratios varied in different parts of the Yangtze depending on the nature of the geological block(s) in each part of the basin and that the riverbed sediments in the middle to lower parts of the mainstream were derived mainly from the Songpan-Garze terrane and Yangtze Block; this result is consistent with our results shown in Fig. 8a. While they reported an absence of coherent downstream variations in isotope ratios in the mainstream, they also did not take into account the effects of eroding sediments along the middle to lower parts of the river, as discussed above. Thus, our results based on mixing calculations do not necessarily contradict their results.

In summary, the average predicted ESR signal intensities of the fine-silt fraction along the modern mainstream are consistent with analyzed values, when incomplete mixing of tributary waters and eroded materials are taken into account. Therefore, ESR signal intensities of the sediments at the rivermouth should record the relative contributions of sediments discharged from each part of the Yangtze River basin.

\section{Distinguishing the provenance of the fine-silt fraction of sediments in the Yangtze drainage basin using ESR signal intensity data from sediments at the rivermouth}

In this section, we examine whether it is possible to distinguish the provenance of the fine-silt fraction of sediments at the rivermouth using ESR signal intensity and
$\mathrm{CI}$ values, especially the relative contributions of sediments from two tributary groups within the Yangtze drainage basin: the western plus northeastern tributaries and the southeastern tributaries, as shown in Fig. 9.

Using Eqs. (1) to (6), the ESR signal intensity of sediments discharged from each tributary group can be calculated as

$$
R_{\text {tri }}=Q_{\text {tri }} / Q_{\text {trig }}
$$

where $Q_{\text {trig }}$ is the total quartz load in the tributary group, $R_{\text {tri }}$ is the contribution ratio of quartz from each tributary to the total quartz load within the tributary group, and $Q_{\text {tri }}$ is the fine-silt fraction of the quartz load from the tributary, as defined in Eq. (1), such that

$$
\mathrm{ESR}_{\text {trig }}=\mathrm{ESR}_{\text {tri1 }} \times R_{\text {tri1 }}+\mathrm{ESR}_{\text {tri2 }} \times R_{\text {tri2 }}+\ldots,
$$

where $E S R_{\text {trig }}$ is the predicted ESR signal intensity of sediments from each tributary group and $\mathrm{ESR}_{\text {tril }}$, ESRtri2 $\ldots$ are the ESR signal intensities of sediments from each tributary within the tributary group.

These calculations were performed for each of the minimum, average, and maximum ESR signal intensities listed in Table 1. The ESR signal intensity of sediments discharged from the western plus northeastern tributary group shows an average of 4.3 , a minimum of 2.5 , and a maximum of 6.3 , while those from the southeastern tributary group show an average of 14.3, a minimum of 12.8 , and a maximum of 16.3. Thus, the ESR signal intensities of the two groups do not overlap one another. Assuming that the sediments at the rivermouth represent a mixture of these two end-members, we can therefore use the ESR signal intensity to estimate the relative contributions of sediments from the western plus northeastern tributaries and the southeastern tributaries to the total sediment load at the rivermouth.

\section{Conclusions}

Meteorological data suggest that changes in the strength of the EASM correspond to changes in the spatial distribution of monsoon precipitation in the Yangtze drainage basin. Thus, reconstruction of temporal changes in the provenance of sediments in the basin could be a useful approach for reconstructing changes in EASM intensity in the past, based on sediment records preserved at the rivermouth.

In this study, riverbed sediments taken from the Yangtze mainstream and its major tributaries were analyzed in terms of their ESR signal intensity and CI values of quartz in three different size fractions of sediment, to distinguish the sources of sediments derived from the different regions of the Yangtze drainage basin. The results suggest that sediment from the different tributaries can be categorized into four groups based on the geological block(s) 
exposed within the drainage basins of each tributary and that each group exhibits a characteristic distribution of ESR signal intensity and CI values. The first group, corresponding to the Yidun Arc and the southwestern margin of the Yangtze Block, is characterized by intermediate ESR values $(\sim 7)$ and low CI values (7.9-8.2). The second group, corresponding to the Songpan-Garze terrain, is characterized by lower ESR values $(<5)$ and a wide range of CI values (8-9). The third group, corresponding to the Qinling orogenic belt, is characterized by a wide range of ESR values (1-10) and a narrow range of $\mathrm{CI}$ values (8.58.9). The fourth group, corresponding to the southeastern parts of the Yangtze and Cathaysia Blocks, is characterized by high ESR values $(>10)$ and CI values of 8-9.

Theoretical predictions of ESR signal intensities below the junctions of the mainstream and major tributaries were calculated as weighted averages based on quartz discharge levels of the mainstream and each tributary, measured just above the junction. These predicted ESR signal intensities were compared with the measured ESR signal intensities of sediments collected from the mainstream just below the junctions with the tributaries. The analyzed values are in good agreement with the predicted values, within the reproducibility of the ESR analysis, indicating that the analyzed ESR signal intensities of sediments accurately represent the relative contributions of quartz from the mainstream and the tributaries.

In addition, changes in ESR signal intensity and CI values along the mainstream were estimated based on values for quartz in the fine-silt fraction discharged from the major tributaries, assuming complete mixing of sediments from the mainstream and each tributary immediately below the junction. The predicted average ESR signal intensities of riverbed samples are in good agreement with analyzed ESR signal intensities of the same samples, within the reproducibility of the ESR analysis, except for some samples that are insufficiently mixed or affected by smaller tributaries. Thus, we conclude that ESR signal intensity and CI values can be used to estimate the mixing ratios of the fine-silt fraction of sediments from the different tributaries in the Yangtze drainage basin, thereby raising the possibility that changes in the spatial distribution of precipitation within the Yangtze drainage basin can be reconstructed from sediment records at the rivermouth.

\section{Additional file}

Additional file 1: List of the analyzed riverbed sediments collected from the Yangtze drainage basin. (XLS $39 \mathrm{~kb}$ )

\section{Abbreviations}

Cl: Crystallinity index; CX: Cathaysia Block; EASM: East Asian summer monsoon; ESR: Electron spin resonance; ISM: Indian summer monsoon; QC: Quartz content; QL: Qinling orogenic belt; QY: Qamdo Block plus Yidun
Arc; SG: Songpan-Garze terrane; SPM: Suspended particle matter; TGD: Three Gorges Dam; XRD: X-ray powder diffraction; YZ: Yangtze Block

\section{Acknowledgements}

The authors thank P. Wang, S. Li, and the car drivers for their assistance during the field trips in China and K. Nagashima and A. Karasuda for their assistance with the ESR and XRD analyses in Japan. The staff at the Takasaki Advanced Radiation Research Institute, National Institutes for Quantum and Radiological Science and Technology (QST), assisted with $\gamma$-ray irradiation. We also thank Y. Saito, an anonymous reviewer, and H. Kawahata (Editor of PEPS) for their critical reading of the manuscript and many constructive suggestions.

\section{Funding}

This study was supported by the Japan Society for the Promotion of Science (JSPS) KAKENHI Grant Number 23221002 to RT and a Japan-China bilateral joint research project awarded to RT from JSPS and also jointly supported by the National Basic Research Program of China (973 program 2015CB953804) to $\mathrm{HZ}$.

\section{Authors' contributions}

RT designed and directed the projects on the Japan side, helped with the collection of samples, and supervised KS. KS collected the riverbed samples, helped collect the SPM samples, conducted ESR and XRD measurements (including pretreatments and irradiation), and wrote the draft manuscript. $\mathrm{HZ}$ designed and directed the projects on the China side and assisted in the collection of samples. TI helped collect samples in Jul 2011 and Feb 2012. CL and MH planned the field trips in 2011 and 2012, collected SPM samples, helped collect the riverbed samples, and arranged the transportation of samples. KW collected samples in Oct 2012 and helped arrange the transportation of samples. YS helped with the sampling in Sep 2011. All authors read and approved the manuscript.

\section{Competing interests}

The authors declare that they have no competing interests.

\section{Author details}

${ }^{1}$ Department of Earth and Planetary Science, University of Tokyo, 7-3-1 Hongo, Bunkyo, Tokyo 113-0033, Japan. ${ }^{2}$ School of Resource, Environment and Earth Science, Yunnan University, Chenggong District, Kunming 650500, People's Republic of China. ${ }^{3}$ Faculty of Environmental Earth Science, Hokkaido University, Kita 8, Nishi 5, Kita-ku, Sapporo, Hokkaido 060-0808, Japan. ${ }^{4}$ College of Geographic Science, Nanjing Normal University, 1 Wen Yuan Lu, Qixia, Nanjing 210046, China.

Received: 14 April 2016 Accepted: 8 February 2017

Published online: 22 February 2017

\section{References}

Ali JR, Thompson GM, Zhou MF, Song X (2005) Emeishan large igneous province, SW China. LITHOS 79:475-489. doi:10.1016/j.lithos.2004.09.013

Chang J, Li J, Lu D, Zhu X, Lu C, Zhou Y, Deng C (2010) The hydrological effect between Jingjiang River and Dongting Lake during the initial period of Three Gorges Project operation. J Geog Sci 20(5):771-786. doi:10.1007/ s11442-010-0810-9

Chen J, Jahn B (1998) Crustal evolution of southeastern China: Nd and Sr isotopic evidence. Tectonophysics 284:101-133

Chen Z, Li J, Shen H, Wang Z (2001) Yangtze River of China: historical analysis of discharge variability and sediment flux. Geomorphology 41:77-91. doi:10. 1016/50022-1694(02)00028-8

Dai S-B, Lu XX (2010) Sediment deposition and erosion during the extreme flood events in the middle and lower reaches of the Yangtze River. Quat Int 226:411. doi:10.1016/.jquaint.2010.01.026

Dai S-B, Yang S-L, Zhu J, Gao A, Li P (2005) The role of Lake Dongting in regulating the sediment budget of the Yangtze River. Hydrol Earth Syst Sci 9 : 692-698

Deng J, Wang Q, Li G, Li C, Wang C (2014) Tethys tectonic evolution and its bearing on the distribution of important mineral deposits in the Sanjiang region, SW China. Gondwana Res 26(2):419-437. doi:10.1016/j.gr.2013.08.002 
Dong Y, Santosh M (2016) Tectonic architecture and multiple orogeny of the Qinling Orogenic Belt, Central China. Gondowana Res 29(1):1-40. doi:10. 1016/j.gr.2015.06.009

Dong Y, Zhang G, Neubauer F, Liu X, Genser J, Hauzenberger C (2011) Tectonic evolution of the Qinling orogen, China: review and synthesis. J Asian Earth Sci 41:213-237. doi:10.1016/j.jseaes.2011.03.002

Enkelmann E, Weislogel A, Ratschbacher L, Eide E, Renno A, Wooden J (2007) How was the Triassic Songpan-Ganzi basin filled? A provenance study. Tectonics 26:TC4007. doi:10.1029/2006TC002078

Feigl FJ, Fowler WB, Yip KL (1974) Oxygen vacancy model for the $E_{1}{ }^{\prime}$ center in SiO2. Solid State Commun 14:225-229

Gao JH, Jia J, Wang YP, Yang Y, Li J, Bai F, Zou X, Gao S (2015) Variations in quantity, composition and grain size of Changjiang sediment discharging into the sea in response to human activities. Hydrol Earth Syst Sci 19(2):645-655. doi:10.5194/hess-19-645-2015

Han G, Liu C-Q (2004) Water geochemistry controlled by carbonate dissolution: a study of the river waters draining karst-dominated terrain, Guizhou Province, China. Chem Geol 204:1-21. doi:10.1016/j.chemgeo.2003.09.009

Hao F, Guo T, Zhu Y, Cal X, Zou H, Li P (2008) Evidence for multiple stages of oil cracking and thermochemical sulfate reduction in the Puguang gas field, Sichuan Basin, China. Am Assoc Pet Geol Bull 92(5):611-637. doi:10.1306/ 01210807090

Hassan MA, Church M, Yan Y, Slaymaker O (2010) Spatial and temporal variation of in-reach suspended sediment dynamics along the mainstem of Changjiang (Yangtze River), China. Water Resour Res 46:W11551. doi:10.1029/ 2010WR009228

Hayashi S, Murakami S, Xu K-Q, Watanabe M (2008) Effect of the Three Gorges Dam Project on flood control in the Dongting Lake area, China, in a 1998type flood. J Hydro-environ Res 2:148-163. doi:10.1016/j.jher.2008.10.002

He M, Zheng H, Clift PD, Tada R, Wu W, Luo C (2015) Geochemistry of finegrained sediments in the Yangtze River and the implications for provenance and chemical weathering in East Asia. Progr Earth Planet Sci 2:32. doi:10. 1186/s40645-015-0061-6

Hennig T, Wang W, Feng Y, Ou X, He D (2013) Review of Yunnan's hydropower development. Comparing small and large hydropower projects regarding their environmental implications and socio-economic consequences. Renewable Sustainable Energy Rev 27:595. doi:10.1016/j.rser.2013.07.023

Hu Q, Feng S, Guo H, Chen G, Jiang T (2007) Interactions of the Yangtze river flow and hydrologic processes of the Poyang Lake, China. J Hydrol 347:90100. doi:10.1016/j.jhydrol.2007.09.005

Hu B, Yang Z, Wang H, Sun X, Bi N, Li G (2009) Sedimentation in the Three Gorges Dam and the future trend of Changjiang (Yangtze River) sediment flux to the sea. Hydrol Earth Syst Sci 13:2253-2264

Hu B, Wang H, Yang Z, Sun X (2011) Temporal and spatial variations of sediment rating curves in the Changjiang (Yangtze River) basin and their implications. Quat Int 230:34-43. doi:10.1016/j.quaint.2009.08.018

Isozaki Y (2009) Characterization of eolian dust and its sources in the Tarim Basin and their temporal changes during Plio-Pleistocene based on the ESR signal intensity and crystallinity index of quartz. Ph. D. thesis, The University of Tokyo, Tokyo, Japan.

Lane SN, Parsons DR, Best JL, Orfeo O, Kostaschuk RA, Hardy RJ (2008) Causes of rapid mixing at a junction of two large rivers: Rio Parana and Rio Paraguay, Argentina. J Geophys Res 113:F02019. doi:10.1029/2006JF000745

Liu H, Lan H, Liu Y, Zhou Y (2011) Characteristics of spatial distribution of debris flow and the effect of their sediment yield in main downstream of Jinsha River, China. Environ Earth Sci 64:1653-1666. doi:10.1007/s12665009-0409-6

Luo L, Qi J-F, Zhang M-Z, Wang K, Han Y-Z (2014) Detrital zircon U-Pb ages of Late Triassic-Late Jurassic deposits in the western and northern Sichuan Basin margin: constraints on the foreland basin provenance and tectonic implications. Int J Earth Sci (Geol Rundsch) 103:1553-1568. doi:10.1007/ s00531-014-1032-7

Ma Y, Zhang S, Guo T, Zhu G, Cai X, Li M (2008) Petroleum geology of the Puguang sour gas field in the Sichuan Basin, SW China. Mar Pet Geol 25:357370. doi:10.1016/j.marpetgeo.2008.01.010

Mao CP, Chen J, Yuan XY, Yang ZF, Balsam W, Ji JF (2010) Seasonal variation in the mineralogy of the suspended particulate matter of the lower Changjiang River at Nanjing, China. Clay and Clay Minerals 58(5):691-706. doi:10.1346/ CCMN.2010.0580508

Mao CP, Chen J, Yuan XY, Yang ZF, Ji JF (2011) Seasonal variations in the Sr-Nd isotopic compositions of suspended particulate matter in the lower
Changjiang River: provenance and erosion constraints. Chin Sci Bull 56:23712378. doi:10.1007/s11434-011-4589-6

Meng Q-R, Zhang G-W (2000) Geologic framework and tectonic evolution of the Qinling orogen, central China. Tectonophysics 323:183-196. doi:10.1016/ S0040-1951(00)00106-2

Murata KJ, Norman MB (1976) An index of crystallinity of quartz. Am J Sci 276: $1120-1130$

Nagashima K, Tada R, Tani A, Toyoda S, Sun Y, Isozaki Y (2007) Contribution of aeolian dust in Japan Sea sediments estimated from ESR signal intensity and crystallinity of quartz. Geochem Geophys Geosyst 8:Q02Q04. doi:10.1029/ 2006GC001364

Qin J-F, Lai S-C, Grapes R, Diwu C, Ju Y-J, Li Y-F (2010) Origin of Late Triassic high-Mg adakitic granitoid rocks from the Dongjiangkou area, Qinling orogen, central China: implications for subduction of continental crust. Lithos 120:347-367. doi:10.1016/j.lithos.2010.08.022

Rea DK, Janecek TR (1981) 25. Mass-accumulation rates of the non-authigenic inorganic crystalline (eolian) component of deep-sea sediments from the western Mid-Pacific Mountains, Deep Sea Drilling Project Site 463. Initial Reports of the Deep Sea Drilling Project 62:653-659. doi:10.2973/dsdp.proc 62.125 .1981

Reid AJ, Wilson CJL, Liu S (2005a) Structural evidence for the Permo-Triassic tectonic evolution of the Yidun Arc, eastern Tibetan plateau. J Struct Geol 27(1):119-137. doi:10.1016/j.jsg.2004.06.011

Reid AJ, Folwer AP, Phillips D, Wilson CJL (2005b) Thermochronology of the Yidun Arc, central eastern Tibetan Plateau: constraints from ${ }^{40} \mathrm{Ar} /{ }^{39} \mathrm{Ar} \mathrm{K}-$ feldspar and apatite fission track data. J Asian Earth Sci 25:915-935. doi:10. 1016/j.jseaes.2004.09.002

Roger F, Jolivet M, Malavieille J (2008) Tectonic evolution of the Triassic fold belts of Tibet. Compt Rendus Geosci 340:180-189. doi:10.1016/j.crte.2007.10.014

Sun Y, Tada R, Chen J, Chen H, Toyoda S, Tani A, Isozak Y, Nagashima K, Hasegawa H, Ji J (2007) Distinguishing the sources of Asian dust based on electron spin resonance signal intensity and crystallinity of quartz. Atmos Environ 41:8537-8548. doi:10.1016/j.atmosenv.2007.07.014

Tada R, Sato S, Irino T, Matsui H, Kennett JP (2000) Millennial-scale compositional variations in late Quaternary sediments at site 1017, southern California. Proc Ocean Drill Program Sci Results 167:277-296. doi:10.2973/odp.proc.Sr.167.222.2000

Tada R, Zheng H, Clift PD (2016) Evolution and variability of the Asian monsoon and its potential linkage with uplift of the Himalaya and Tibetan Plateau. Progr Earth Planet Sci 3:4. doi:10.1186/s40645-016-0080-y

Teraoka Y, Okamura K (2003) Geological map of East Asia. Geological Survey of Japan, AIST

Teraoka Y, Okamura K (2007) Geological map of Central Asia. Geological Survey of Japan, AIST

Toyoda S (1992) Production and decay characteristics of paramagnetic defects in quartz: applications to ESR dating. Ph.D. thesis, Osaka University, Toyonaka, Osaka, Japan.

Toyoda S, Hattori W (2000) Formation and decay of the $E_{1}{ }^{\prime}$ center and of its precursor. Appl Radiat Isot 52:1351-1356

Toyoda S, Naruse T (2002) Eolian dust from the Asian deserts to the Japanese islands since the Last Glacial Maximum: the basis for ESR method. Transactions, Jpn Geomorphol Union 23:811-820

USGS (2004) Shuttle radar topography mission, 3 Arc Second, Version 2.1, Global Land Cover Facility, University of Maryland, College Park, Maryland, February 2000.

Wang B, Lin H (2002) Rainy season of the Asian-Pacific summer monsoon. J Clim 15(4):386-398. doi:10.1175/1520-0442(2002)015<0386:RSOTAP > 2.0.CO;2

Wang X, Metcalfe I, Jian P, He L, Wang C (2000) The Jinshajiang-Ailaoshan Suture Zone, China: tectonostratigraphy, age and evolution. J Asian Earth Sci 18(6): 675-690. doi:10.1016/S1367-9120(00)00039-0

Wang X-L, Zhou J-C, Griffin WL, Wang R-C, Qiu J-S, O'Reilly SY, Xu X, Liu X-M, Wang $X-L$ (2007a) Detrital zircon geochronology of Precambrian basement sequences in the Jiangnan orogen: dating the assembly of the Yangtze and Cathaysia Blocks. Precambrian Res 159:117-131. doi:10.1016/j.precamres.2007.06.005

Wang Z-Y, Li Y, He Y (2007b) Sediment budget of the Yangtze River. Water Resour Res 43:W04401. doi:10.1029/2006WR005012

Wang Y, Zhanf F, Fan W, Zhang G, Chen S, Cawood PA, Zhang A (2010) Tectonic setting of the South China Block in the early Paleozoic: resolving intracontinental and ocean closure models from detrital zircon U-Pb geochronology. Tectonics 29:TC6020. doi:10.1029/2010TC002750

Wang Y, Fan W, Zhang G, Zhang Y (2013) Phanerozoic tectonics of the South China Block: key observations and controversies. Gondwana Res 23:1273-1305. doi:10.1016/j.gr.2012.02.019 
Wu W, Xu S, Yang J, Yin H, Tao X (2009) Sr fluxes and isotopic compositions in the headwaters of the Yangtze River, Tongtian River and Jinsha River originating from the Qinghai-Tibet Plateau. Chem Geol 260:63-72. doi:10. 1016/j.chemgeo.2008.12.007

Xia L, Li X, Ma Z, Xu X, Xia Z (2011) Cenozoic volcanism and tectonic evolution of the Tibetan plateau. Gondwana Res 19:850-866. doi:10.1016/j.gr.2010.09.005

Xu K, Milliman JD, Xu H (2010) Temporal trend of precipitation and runoff in major Chinese Rivers since 1951. Global Planet Change 73:219-232. doi:10. 1016/j.gloplacha.2010.07.002

Yang S-L, Zhao Q-Y, Belkin IM (2002) Temporal variation in the sediment load of the Yangtze river and the influences of human activities. J Hydrol 263:56-71. doi:10.1016/50022-1694(02)00028-8

Yang Z, Wang H, Saito Y, Milliman JD, Xu K, Qiao S, Shi G (2006) Dam impacts on the Changjiang (Yangtze) River sediment discharge to the sea: the past 55 years and after Three Gorges Dam. Water Resour Res 42:W004407. doi:10. 1029/2005WR003970

Yang S-L, Zhang J, Xu XJ (2007) Influence of the Three Gorges Dam on downstream delivery of sediment and its environmental implications, Yangtze River. Geophys Res Lett 34:L10401. doi:10.1029/2007GL029472

Yang S-L, Milliman JD, Xu K-H, Deng B, Zhang XX, Luo XX (2014) Downstream sedimentary and geomorphic impacts of the Three Gorges Dam on the Yangtze River. Earth Sci Rev 138:469-486. doi:10.1016/j.earscirev.2014.07.006

Yin A, Harrison TM (2000) Geologic evolution of the Himalayan-Tibetan orogen. Annu Rev Earth Planet Sci 28:211-280. doi:10.1146/annurev.earth.28.1.211

Yin H, Liu G, Pi J, Chen G, Li C (2007) On the river-lake relationship of the middle Yangtze reaches. Geomorphology 85:197-207. doi:10.1016/j.geomorph.2006. 03.017

Zhang Q, Xu C-Y, Zhang Z, Chen YD, Liu C-L, Lin H (2008) Spatial and temporal variability of precipitation maxima during 1960-2005 in the Yangtze River basin and possible association with large-scale circulation. J Hydrol 353:215227. doi:10.1016/j.jhydrol.2007.11.023

Zhang Y, Huang CC, Pang J, Zha X, Zhou Y, Yin S, Wang J (2012) Comparative study of the modern flood slackwater deposits in the upper reaches of Hanjiang and Weihe River Valleys, China. Quat Int 282:184-191. doi:10.1016/j. quaint.2012.03.056

Zong Y, Chen X (2000) The 1998 Flood on the Yangtze, China. Nat Hazards 22: 165-184. doi:10.1023/A:1008119805106

\section{Submit your manuscript to a SpringerOpen ${ }^{\circ}$ journal and benefit from:}

- Convenient online submission

- Rigorous peer review

- Immediate publication on acceptance

- Open access: articles freely available online

- High visibility within the field

- Retaining the copyright to your article

Submit your next manuscript at $\boldsymbol{s p r i n g e r o p e n . c o m ~}$ 